\title{
Resveratrol-Loaded Hydrogel Contact Lenses with Antioxidant and Antibiofilm Performance
}

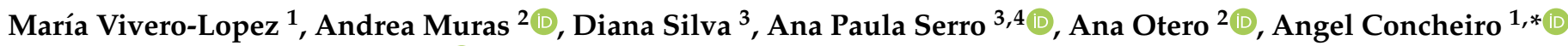 \\ and Carmen Alvarez-Lorenzo $1, *$ (1)
}

1 Departamento de Farmacología, Farmacia y Tecnología Farmacéutica, I+D Farma (GI-1645), Facultad de Farmacia and Health Research Institute of Santiago de Compostela (IDIS), Universidade de Santiago de Compostela, 15782 Santiago de Compostela, Spain; mariavivero.lopez@usc.es

2 Departamento de Microbiología, Facultad de Biología, Edificio CIBUS, Universidade de Santiago de Compostela, 15782 Santiago de Compostela, Spain; andrea.muras@usc.es (A.M.); anamaria.otero@usc.es (A.O.)

3 Centro de Química Estrutural, Instituto Superior Técnico, Universidade de Lisboa, Av. Rovisco Pais, 1049-001 Lisboa, Portugal; dianacristinasilva@tecnico.ulisboa.pt (D.S.); anapaula.serro@tecnico.ulisboa.pt (A.P.S.)

4 CIIEM, Instituto Superior de Ciências da Saúde Egas Moniz, Campus Universitário, Quinta da Granja, Monte de Caparica, 2829-511 Caparica, Portugal

* Correspondence: angel.concheiro@usc.es (A.C.); carmen.alvarez.lorenzo@usc.es (C.A.-L.); Tel.: +34-881-815-239 (A.C.)

check for updates

Citation: Vivero-Lopez, M.; Muras, A.; Silva, D.; Serro, A.P.; Otero, A.; Concheiro, A.; Alvarez-Lorenzo, C. Resveratrol-Loaded Hydrogel Contact Lenses with Antioxidant and Antibiofilm Performance.

Pharmaceutics 2021, 13, 532.

https://doi.org/10.3390/

pharmaceutics 13040532

Academic Editor: Charles Heard

Received: 15 February 2021

Accepted: 6 April 2021

Published: 11 April 2021

Publisher's Note: MDPI stays neutral with regard to jurisdictional claims in published maps and institutional affiliations.

Copyright: (c) 2021 by the authors Licensee MDPI, Basel, Switzerland. This article is an open access article distributed under the terms and conditions of the Creative Commons Attribution (CC BY) license (https:// creativecommons.org/licenses/by/ $4.0 /)$

\begin{abstract}
Contact lenses (CLs) are prone to biofilm formation, which may cause severe ocular infections. Since the use of antibiotics is associated with resistance concerns, here, two alternative strategies were evaluated to endow CLs with antibiofilm features: copolymerization with the antifouling monomer 2-methacryloyloxyethyl phosphorylcholine (MPC) and loading of the antioxidant resveratrol with known antibacterial activity. MPC has, so far, been used to increase water retention on the CL surface (Proclear ${ }^{\circledR} 1$ day CLs). Both poly(hydroxyethyl methacrylate) (HEMA) and silicone hydrogels were prepared with MPC covering a wide range of concentrations (from 0 to $101 \mathrm{mM}$ ). All hydrogels showed physical properties adequate for CLs and successfully passed the hen's eggchorioallantoic membrane (HET-CAM) test. Silicone hydrogels had stronger affinity for resveratrol, with higher loading and a slower release rate. Ex vivo cornea and sclera permeability tests revealed that resveratrol released from the hydrogels readily accumulated in both tissues but did not cross through. The antibiofilm tests against Pseudomonas aeruginosa and Staphylococcus aureus evidenced that, in general, resveratrol decreased biofilm formation, which correlated with its concentrationdependent antibacterial capability. Preferential adsorption of lysozyme, compared to albumin, might also contribute to the antimicrobial activity. In addition, importantly, the loading of resveratrol in the hydrogels preserved the antioxidant activity, even against photodegradation. Overall, the designed hydrogels can host therapeutically relevant amounts of resveratrol to be sustainedly released on the eye, providing antibiofilm and antioxidant performance.
\end{abstract}

Keywords: antibiofilm; antioxidant; drug-eluting contact lenses; microbial keratitis; endophthalmitis; device-related ocular infections

\section{Introduction}

The surfaces of contact lenses (CLs) and intraocular lenses (IOLs) are quite prone to the formation of bacterial biofilms, which may cause severe infections in the ocular structures [1,2]. Although CL materials have undergone a profound evolution over the last few years, the incidence of microbial-related ocular diseases has not decreased [3]. Approximately 4.2 out of 10,000 CL wearers suffer from microbial keratitis, mainly caused by bacteria (>90\%) [4]. CL wearing continues to be the most relevant risk factor for the development of microbial keratitis, although not all CLs are the same in terms of being prone 
to bacterial growth $[1,2,5,6]$. The risk increases in the following order: daily wear rigid gas permeable CLs $<$ daily wear soft CLs $<$ extended (overnight) wear CLs $[1,5,7]$. Bacteria can come into contact with the eye through the fingers when inserting and removing the lens or through the CL itself if the care solutions or storage cases are contaminated [1]. Once the $\mathrm{CL}$ is inserted into the eye, proteins and other tear components adsorb onto its surface, which facilitates the adhesion of bacteria. Bacterial biofilms grown on CLs play a crucial role in keratitis disease, being generally associated with the Gram-negative Pseudomonas aeruginosa and the Gram-positive Staphylococcus aureus [1-3,6]. Ocular biofilms can remain on the CL surface for long periods of time, regularly releasing planktonic cells and bacterial products such as endotoxins that can damage the corneal epithelium and induce other ophthalmic diseases, such as dry eye [2,8]. CLs do not only support biofilm formation but also interfere with the normal host defense mechanisms, such as tearing and blinking, and modify the corneal epithelium, facilitating the adhesion and colonization by opportunistic bacteria $[2,5,7]$. Once bacteria adhere to the injured corneal epithelium, microbial keratitis can progress [1].

Biofilm formation is also a problem for the safety of IOLs. After placement of an IOL in cataract surgery, patients may develop endophthalmitis, a serious form of intraocular inflammation caused by the introduction of a microbial pathogen in the posterior segment of the eye [5,9]. The process starts with the contamination of IOLs with bacteria that can be present in the conjunctiva (e.g., S. epidermidis, S. aureus or P. aeruginosa) during insertion and their subsequent transport from the ocular surface to the posterior chamber. The relatively static environment of vitreous humor favors the development of the biofilm and the associated infection [5]. Overall, although CLs and IOLs have shown great success in improving vision problems, the incidence of eye infections associated with these devices represents a significant concern regarding their use. Hence, the development of new lenses with antibiofilm substances in their composition is receiving increasing attention $[3,10]$.

Consequently, 2-Methacryloyloxyethyl phosphorylcholine (MPC) (Figure 1) has been explored to endow polymeric networks with improved biocompatibility and proteinresistant surfaces [11-16]. MPC is highly hydrophilic and its bioinspired phosphorylcholine group resembles the phospholipid headgroups present in the cell membrane. In this regard, CLs made of copolymers of 2-hydroxyethyl methacrylate (HEMA) and MPC, commercially available as Proclear ${ }^{\circledR}$, claim to remain wet for prolonged periods of time and thus to provide improved comfort to the wearers [17]. Surface grafting of MPC has been shown to enhance the ocular tolerance of hydrophobic acrylic IOLs [13] and silicone IOLs [18]. Furthermore, antifouling coatings based on MPC may provide biomaterials with higher wettability and lower protein adsorption [19] and have been shown to be useful to prevent the adhesion of bacteria due to the formation of highly hydrated, flexible interfaces that avoid the deposition of conditioning substances [20].

In parallel to the design of surfaces that may prevent the adhesion of bacteria, the incorporation into the lenses of natural compounds that can act as biofilm inhibitors is gaining attention. In this regard, resveratrol (trans-3,5,4'-trihydroxystilbene) (Figure 1), which is a natural antioxidant polyphenol [21] with good ocular tolerance [22,23], has been reported to interfere in vitro with the bacterial communication process known as quorum sensing (QS) and to inhibit biofilm formation by clinically relevant bacteria such as S. aureus, P. aeruginosa and Vibrio cholerae [24-27]. The interference in QS processes may increase the susceptibility to antibiotics and downregulate natural, industrial and clinical biofilms [28,29]. Resveratrol is also believed to cause bacterial growth inhibition due to a combination of mechanisms involving membrane damage and inhibition of ATP synthase and efflux pumps, which facilitates the intracellular accumulation of other antimicrobial substances [30,31]. The minimum inhibitory concentration (MIC) of resveratrol for the Gram-positive S. aureus, Streptococcus pyogenes and Enterococcus faecalis was reported to be between 100 and $200 \mu \mathrm{g} / \mathrm{mL}$; meanwhile, Gram-negative bacteria such as P. aeruginosa, E. coli or Klebsiella pneumoniae showed lower susceptibility to resveratrol [32]. 
This work relies on the hypothesis that the design of hydrogels containing MPC moieties and incorporating resveratrol may exhibit a synergism in terms of the prevention of biofilm formation on CLs, while resveratrol may also lead to other beneficial effects related to its antioxidant capability. Some eye diseases caused by oxidative stress mechanisms, such as age-related macular degeneration, cataracts and glaucoma, may be treated or prevented with antioxidants [23,33]. To the best of our knowledge, loading of resveratrol in CLs has not been tested before. Thus, the aim of this work was to prepare hydrogel CLs and silicone hydrogel CLs containing MPC and loaded with resveratrol to decrease the incidence of ocular infections and manage some eye diseases caused by oxidative stress mechanisms. To carry out the work, hydrogels were prepared covering a wide range of MPC ratios and then the loading and release profiles of resveratrol were evaluated. An extensive characterization of the materials, comprising the evaluation of their protein adsorption and antibiofilm and antioxidant capabilities, was performed. Commercially available Proclear ${ }^{\circledR} 1$ day CLs were used as a control for comparison purposes.<smiles>C=C(C)C(=O)OCCOP(=O)([O-])OCC[N+](C)(C)C</smiles>

(a) MPC<smiles>C=C(C)C(=O)OCCC[Si](O[Si](C)(C)C)(O[Si](C)(C)C)O[Si](C)(C)C</smiles>

(b) resveratrol<smiles>Oc1ccc(C=Cc2cc(O)cc(O)c2)cc1</smiles><smiles>C=CN1CCCC1=O</smiles>

(e) NVP<smiles>C=C(C)C(=O)OCCO</smiles>

(c) HEMA

Figure 1. Chemical structure of (a) 2-methacryloyloxyethyl phosphorylcholine (MPC), (b) trans-resveratrol, (c) 2-hydroxyethyl methacrylate (HEMA), (d) 3-(methacryloyloxy)propyltris(trimethylsiloxy)silane (TRIS), (e) Nvinylpyrrolidone (NVP) and (f) ethylene glycol dimethacrylate (EGDMA).

\section{Materials and Methods}

\subsection{Materials}

Firstly, 3-(Methacryloyloxy)propyltris(trimethylsiloxy)silane (TRIS) was from Alfa Aesar by Thermo Fisher (Thermo Fisher, Kandel, Germany); 2-Hydroxyethyl methacrylate (HEMA), (3-(4,5-dimethylthiazol-2-yl)-2,5-diphenyltetrazolium bromide) (MTT), calcium chloride dihydrate $\left(\mathrm{CaCl}_{2} \cdot 2 \mathrm{H}_{2} \mathrm{O}\right)$ and sodium dihydrogen phosphate monohydrate $\left(\mathrm{NaH}_{2} \mathrm{PO}_{4} \cdot \mathrm{H}_{2} \mathrm{O}\right)$ were from Merck KGaA (Merck KGaA, Darmstadt, Germany); 2-Methacryloyloxyethyl phosphorylcholine (MPC), 1-vinyl-2-pyrrolidinone, ethylene glycol dimethacrylate (EGDMA), dichlorodimethylsilane, 2,2'-azobis(2-methylpropionitrile) (AIBN), 2,2-diphenyl-1-picrylhydrazyl and lysozyme from chicken egg white were from Sigma-Aldrich (Sigma-Aldrich, St. Louis, MO, USA). Resveratrol was from ChemCruz, Santa Cruz Biotechnology Inc. (Santa Cruz Biotechnology Inc., Dallas, TX, USA). Albumin bovine fraction V standard grade ( $\mathrm{pH} 7$ ) was from SERVA Electrophoresis GmbH (SERVA Electrophoresis $\mathrm{GmbH}$, Heidelberg, Germany). Di-sodium hydrogen phosphate anhydrous $\left(\mathrm{Na}_{2} \mathrm{HPO}_{4}\right)$, magnesium chloride 6-hydrate $\left(\mathrm{MgCl}_{2} \cdot 6 \mathrm{H}_{2} \mathrm{O}\right)$ and potassium di-hydrogen phosphate $\left(\mathrm{KH}_{2} \mathrm{PO}_{4}\right)$ were from PanReac Química S.L.U. (Química S.L.U., Barcelona, Spain). Sodium bicarbonate $\left(\mathrm{NaHCO}_{3}\right)$ was from Probus S.A. (Probus S.A., Barcelona, Spain). Potassium chloride $(\mathrm{KCl})$, sodium chloride $(\mathrm{NaCl})$ and calcium chloride anhydrous $\left(\mathrm{CaCl}_{2}\right)$ were from Scharlab S.L. (Scharlab S.L., Barcelona, Spain). Ethanol absolute 99.9\% and sodium hydroxide $(\mathrm{NaOH})$ were from VWR Chemicals (VWR Chemicals, FontenarySous-Bois, France). Bacto ${ }^{\mathrm{TM}}$ tryptone and bacto ${ }^{\mathrm{TM}}$ yeast extract were from Becton, Dickinson and Company (Becton, Dickinson and Company, Le Pont de Claix, France) and tryptic soy broth (TSB) was from Oxoid S.A. (Oxoid S.A., Madrid, Spain). Ultrapure water (resistivity $>18.2 \mathrm{M} \Omega \cdot \mathrm{cm}$ ) was obtained by reverse osmosis (MilliQ ${ }^{\circledR}$, Millipore Ibérica, Madrid, Spain). 
Phosphate-buffered saline (PBS) medium was prepared with $8 \mathrm{~g}$ of $\mathrm{NaCl}, 0.3 \mathrm{~g}$ of $\mathrm{KCl}$, $0.73 \mathrm{~g}$ of $\mathrm{Na}_{2} \mathrm{HPO}_{4}$ and $0.2 \mathrm{~g}$ of $\mathrm{KH}_{2} \mathrm{PO}_{4}$ for $1 \mathrm{~L}$ with $\mathrm{pH}$ 6.5. Carbonate buffer was prepared with $1.24 \mathrm{~g}$ of NaCl, $0.071 \mathrm{~g}$ of $\mathrm{KCl}, 0.02 \mathrm{~g}$ of $\mathrm{NaH}_{2} \mathrm{PO}_{4} \cdot \mathrm{H}_{2} \mathrm{O}, 0.49 \mathrm{~g}$ of $\mathrm{NaHCO}_{3}, 0.023 \mathrm{~g}$ of $\mathrm{CaCl}_{2}$ and $0.031 \mathrm{~g}$ of $\mathrm{MgCl}_{2} \cdot 6 \mathrm{H}_{2} \mathrm{O}$ for $200 \mathrm{~mL}$ with $\mathrm{pH}$ 7.2. Simulated lachrymal fluid (SLF) was prepared with the following composition: $6.78 \mathrm{~g} / \mathrm{L} \mathrm{NaCl}, 2.18 \mathrm{~g} / \mathrm{L} \mathrm{NaHCO}_{3}$, $1.38 \mathrm{~g} / \mathrm{L} \mathrm{KCl}$ and $0.084 \mathrm{~g} / \mathrm{L} \mathrm{CaCl}_{2} \cdot 2 \mathrm{H}_{2} \mathrm{O}$ with $\mathrm{pH} 7.5$ [34]. Proclear ${ }^{\circledR} 1$ day CLs (Omafilcon A, CooperVision ${ }^{\circledR}$, Lake Forest, CA, USA), diopter -3.00 , water content $60 \%$, Dk/t 28, were acquired from a local optical store.

\subsection{Hydrogel Synthesis}

Different monomer solutions (Table 1) were prepared at room temperature under magnetic stirring (400 rpm). EGDMA was used as crosslinker and AIBN as initiator. The monomer solutions were injected ( $25 \mathrm{G}$ needle) into molds made of presilanized glass plates $(12 \times 14 \mathrm{~cm}$ ) fixed with $0.30 \mathrm{~mm}$ Teflon frame (silicone-hydrogels) or $0.45 \mathrm{~mm}$ silicone frame (HEMA-hydrogels). The polymerization was carried out at $50{ }^{\circ} \mathrm{C}$ for $12 \mathrm{~h}$ and at $70{ }^{\circ} \mathrm{C}$ for other $24 \mathrm{~h}$.

Table 1. Hydrogels composition *.

\begin{tabular}{lccccccc}
\hline Hydrogel & Code & $\begin{array}{c}\text { MPC } \\
(\mathbf{m g})\end{array}$ & $\begin{array}{c}\text { TRIS } \\
(\mathbf{m L})\end{array}$ & $\begin{array}{c}\text { NVP } \\
(\mathbf{m L})\end{array}$ & $\begin{array}{c}\text { HEMA } \\
(\mathbf{m L})\end{array}$ & $\begin{array}{c}\text { EGDMA } \\
(\boldsymbol{\mu L} \mathbf{)}\end{array}$ & $\begin{array}{c}\text { AIBN } \\
(\mathbf{m g})\end{array}$ \\
\hline \multirow{6}{*}{ Silicone } & S1 & 0 & 1.58 & 2.50 & 0.92 & 32 & 12.50 \\
& $\mathrm{~S} 2$ & 14.76 & 1.58 & 2.50 & 0.92 & 32 & 12.50 \\
& $\mathrm{~S} 3$ & 29.52 & 1.58 & 2.50 & 0.92 & 32 & 12.50 \\
& $\mathrm{~S} 4$ & 44.29 & 1.58 & 2.50 & 0.92 & 32 & 12.50 \\
& $\mathrm{~S} 5$ & 118.1 & 1.58 & 2.50 & 0.92 & 32 & 12.50 \\
& $\mathrm{~S} 6$ & 150.0 & 1.58 & 2.50 & 0.92 & 32 & 12.50 \\
\hline \multirow{6}{*}{ HEMA } & H1 & 0 & - & - & 4 & 6.04 & 6.57 \\
& $\mathrm{H} 2$ & 11.81 & - & - & 4 & 6.04 & 6.57 \\
& $\mathrm{H} 3$ & 23.62 & - & - & 4 & 6.04 & 6.57 \\
& $\mathrm{H} 4$ & 35.43 & - & - & 4 & 6.04 & 6.57 \\
& $\mathrm{H} 5$ & 70.90 & - & - & 4 & 6.04 & 6.57 \\
& $\mathrm{H} 6$ & 120.0 & - & - & 4 & 6.04 & 6.57 \\
\hline
\end{tabular}

* MPC: 2-methacryloyloxyethyl-phosphorylcholine, TRIS: 3-(methacryloyloxy)propyltris (trimethylsiloxy)silane NVP: N-vinylpyrrolidone; HEMA: 2-hydroxyethyl methacrylate; EGDMA: ethyleneglycol dimethacrylate; AIBN: 2,2'-azobis(2-methylpropionitrile).

After polymerization, hydrogel sheets were demolded by injecting a small amount of water into the molds with a syringe, washed in $1 \mathrm{~L}$ of boiling distilled water for $15 \mathrm{~min}$ to remove unreacted monomers and cut with punches into different sizes according to the needs of each test. Hydrogel pieces were washed in MilliQ ${ }^{\circledR}$ water $(1 \mathrm{~L})$ at room temperature, replacing the medium two or three times per day until the complete removal of unreacted monomers, which was confirmed by measuring the absorbance of aliquots of the washing medium (UV-Vis spectrophotometer Agilent 8453, Waldbronn, Germany), and dried at $70{ }^{\circ} \mathrm{C}$ for $24 \mathrm{~h}$. Proclear ${ }^{\circledR} 1$ day CLs were washed using the same procedure and dried at $40^{\circ} \mathrm{C}$ for $2 \mathrm{~h}$ and $70^{\circ} \mathrm{C}$ for a further $2 \mathrm{~h}$. Some hydrogel pieces were directly freezedried and scanning electron microscopy (SEM) images of their surfaces were recorded (FESEM Zeiss Ultra Plus, Oberkochen, Germany).

\subsection{Water Uptake}

Dry Proclear ${ }^{\circledR} 1$ day CLs and discs of each hydrogel (10 mm diameter) were weighed and placed into Falcon ${ }^{\circledR}$ tubes with $5 \mathrm{~mL}$ of water, SLF or resveratrol solution $(100 \mu \mathrm{g} / \mathrm{mL}$ in ethanol:water 10:90 $v / v$ ) at room temperature. Three replicates were tested. At preset times (each hour during the first $8 \mathrm{~h}$ and then every $24 \mathrm{~h}$ for 5 days), the discs were weighed after carefully wiping their surfaces with absorbent paper to remove excess water. The 
increase in weight was recorded to calculate the water uptake as a percentage using the following Equation (1).

$$
\text { Water uptake }(\%)=\frac{W_{t}-W_{0}}{W_{0}} \times 100
$$

In this equation, $W_{0}$ and $W_{t}$ represent the weight of dry hydrogel and swollen hydrogel at time $t$, respectively.

\subsection{Transmittance}

The light transmittance (\%) of swollen hydrogel discs and Proclear ${ }^{\circledR} 1$ day CLs was recorded using a UV-Vis spectrophotometer (Agilent Cary 60 UV-Vis, Waldbronn, Germany) from 200 to $700 \mathrm{~nm}$ with $1 \mathrm{~nm}$ intervals. All the measurements were carried out at least in triplicate after swelling in water, SLF and resveratrol solution $(100 \mu \mathrm{g} / \mathrm{mL}$ in ethanol:water 10:90 $v / v)$.

\subsection{Wettability}

The wettability of the hydrogels was determined by the captive bubble method, following a methodology described previously [35]. Hydrogel discs (10 mm in diameter) were hydrated in $5 \mathrm{~mL}$ of water for at least $24 \mathrm{~h}$. Then, the discs were placed horizontally in a measuring cell filled with water. Air bubbles $(3-4 \mu \mathrm{L})$ were formed and released underneath the inferior surface of the discs, using a micrometer syringe with an endcurved needle. The bubbles adhered to the hydrogel surface and the water contact angle was measured as the angle formed between the hydrogel surface and the tangent to the bubble at the triple point where water/air/hydrogel coexists (Figure S1, Supplementary Information). Images were taken at set time intervals for 1 min using a video camera (JAI CV-A50, Copenhagen, Denmark) mounted on an optical microscope (Wild M3Z, Leica Microsystems, Jena, Germany) and connected to a frame grabber (Data Translation DT3155, Measuring Computing Corp., Norton, MA, USA). The acquisition and analysis of the images were performed using the ADSA-P software (Axisymmetric Drop Shape Analysis Profile; Applied Surface Thermodynamics Research Associates, Toronto, Canada). Three discs were used for each formulation, and eight to ten bubbles were created for each disc; in total, there were 30 bubbles per formulation.

\subsection{Mechanical Properties}

HEMA- and silicone-hydrogel-hydrated (in water) strips $(16 \times 9 \mathrm{~mm})$ were fixed at room temperature to the upper and lower clamps (gap $7 \mathrm{~mm}$ ) of a TA.XT Plus Texture Analyzer (Stable Micro Systems, Ltd., Surrey, UK) fitted with a $5 \mathrm{Kg}$ load cell. Stress-strain plots were recorded at a crosshead speed of $0.1 \mathrm{~mm} \cdot \mathrm{s}^{-1}$ at least in triplicate. Young's modulus was calculated from the slope of the linear portion of the stress versus strain curves. The Young's modulus of Proclear ${ }^{\circledR} 1$ day CLs was also evaluated.

\subsection{Resveratrol Loading and Release Tests}

HEMA-hydrogel-dried discs $\left(37^{\circ} \mathrm{C}, 24 \mathrm{~h}\right)$ with $10 \mathrm{~mm}$ diameter (average weight $39 \mathrm{mg})$, silicone-hydrogel-dried discs $\left(37^{\circ} \mathrm{C}, 24 \mathrm{~h}\right)$ with $10 \mathrm{~mm}$ diameter (average weight $13 \mathrm{mg}$ ) and Proclear ${ }^{\circledR} 1$ day dried CLs $\left(37^{\circ} \mathrm{C}, 24 \mathrm{~h}\right)$ with $14.2 \mathrm{~mm}$ diameter (average weight $13 \mathrm{mg}$ ) were placed, in separate Falcon ${ }^{\circledR}$ tubes with $7 \mathrm{~mL}$ of resveratrol in ethanol:water 10:90 $\mathrm{v} / \mathrm{v}$ solution $(100 \mu \mathrm{g} / \mathrm{mL})$. Then, they were placed in an Incubating Mini Shaker (VWR) at $36^{\circ} \mathrm{C}$ and $180 \mathrm{rpm}$ protected from light. The test was carried out in quadruplicate.

The absorbance of the loading solution was monitored at $305 \mathrm{~nm}$ (UV-Vis spectrophotometer Agilent 8534, Waldbronn, Germany) by taking aliquots of $250 \mu \mathrm{L}$ for the first $8 \mathrm{~h}$ and aliquots of $500 \mu \mathrm{L}$ for subsequent measurements (the liquid removed was not replaced with fresh solution). The aliquots were leveled to $5 \mathrm{~mL}$ with ethanol:water 10:90 v/v before absorbance measurement. The amount of resveratrol loaded was calculated from the difference between the initial and the final amount of drug in the solution using a 
validated calibration curve obtained in ethanol:water 10:90 $v / v$ and considering the amount of resveratrol lost in the monitoring. A loading test was also carried out for $72 \mathrm{~h}$ without intermediate measurements. The network/water partition coefficient $\left(\mathrm{K}_{\mathrm{N} / \mathrm{W}}\right)$ was calculated as the difference between the total amount loaded and the amount that could be hosted in the aqueous phase (using the water uptake values) and divided by the concentration of resveratrol in the loading solution [34].

Release experiments were carried out by placing resveratrol-loaded discs (previously rinsed with $\mathrm{NaCl} 0.9 \%$ ) in Falcon ${ }^{\circledR}$ tubes with $6 \mathrm{~mL}$ of $\mathrm{NaCl} 0.9 \%$. The tubes were kept in an Incubating Mini Shaker (VWR) at $36^{\circ} \mathrm{C}$ and $180 \mathrm{rpm}$ protected from light. The test was carried out in quadruplicate. Samples of the medium were taken every hour in the first $8 \mathrm{~h}$ of the experiment, and the absorbance was measured at $305 \mathrm{~nm}$ using a UV-Vis spectrophotometer (Agilent 8534, Waldbronn, Germany). The samples were immediately returned to the corresponding vial, except for HEMA hydrogels and Proclear ${ }^{\circledR} 1$ day CLs. For these hydrogels, aliquots $(1 \mathrm{~mL})$ of the release medium sampled in the 3 to $8 \mathrm{~h}$ interval were replaced with the same volume of $\mathrm{NaCl} 0.9 \%$ fresh solution. Once the $8 \mathrm{~h}$ time point samples were measured, the release medium in all tubes was increased to $12 \mathrm{~mL}$ with the addition of $6 \mathrm{~mL}$ of $\mathrm{NaCl} 0.9 \%$ fresh solution. Therefore, from this time point $(8 \mathrm{~h})$ until $25 \mathrm{~h}$ was reached, the volume of the release medium was $12 \mathrm{~mL}$. At $25 \mathrm{~h}$, HEMA hydrogels and Proclear ${ }^{\circledR} 1$ day CLs were transferred to new Falcon ${ }^{\circledR}$ tubes containing $12 \mathrm{~mL}$ of $\mathrm{NaCl} 0.9 \%$ fresh solution, and the test proceeded for one month. Contrastingly, silicone hydrogels remained in the initial Falcon ${ }^{\circledR}$ tubes since the concentration of resveratrol achieved was quite low. Resveratrol concentration values were calculated from the absorbance at $305 \mathrm{~nm}$ using a calibration curve of resveratrol dissolved in $\mathrm{NaCl} 0.9 \%$ solution. The amounts removed and the corresponding dilution of the sample, if needed, were considered to calculate the total amount released.

\subsection{Resveratrol Stability}

Since trans-resveratrol is highly sensitive to certain light conditions [36], stability during storage under dark and once exposed to various light conditions was investigated. First, solutions of resveratrol in ethanol:water 10:90 $v / v(5 \mu \mathrm{g} / \mathrm{mL})$ and $\mathrm{NaCl} 0.9 \%(6 \mu \mathrm{g} / \mathrm{mL})$ were placed into Falcon ${ }^{\circledR}$ tubes $\left(36^{\circ} \mathrm{C}, 180 \mathrm{rpm}\right)$ for $24 \mathrm{~h}$ and 20 days, respectively, protected from light, and the UV-Vis spectra recorded at preset times (UV-Vis spectrophotometer Agilent 8534, Waldbronn, Germany). The stability of resveratrol in ethanol:water 10:90 v/v (5 $\mu \mathrm{g} / \mathrm{mL})$ against white light (HITACHI 8 W F8T5 daylight, Chiyoda, Japan) (14 cm gap from the lamp) and the light in the working area of the laboratory was also evaluated for $24 \mathrm{~h}$ by monitoring the UV-Vis spectrum. To evaluate the capacity of the hydrogels to protect resveratrol from light degradation, resveratrol-loaded HEMA- and silicone-based hydrogels (soaked in a $100 \mu \mathrm{g} / \mathrm{mL}$ resveratrol in ethanol:water 10:90 $v / v$ solution for $72 \mathrm{~h}$ ) were placed into empty quartz cells and exposed to white light (HITACHI 8 W F8T5 daylight, Chiyoda, Japan) for $3 \mathrm{~h}$ (14 cm gap from the lamp) at room temperature. The amount of resveratrol loaded and released was monitored, following the same procedure as described above.

\subsection{Ex Vivo Corneal and Scleral Permeability Tests}

Resveratrol corneal and scleral permeability tests were carried out, in triplicate, according to a previously described protocol [37] for selected silicone- and HEMA-based hydrogels. The assay was also carried out for resveratrol-loaded Proclear ${ }^{\circledR} 1$ day CLs and a resveratrol solution $(1 \mathrm{~mL}, 70 \mu \mathrm{g} / \mathrm{mL}$ in ethanol:water 10:90 $\mathrm{v} / \mathrm{v})$ prepared considering the maximum amount that the hydrogels could release in $6 \mathrm{~h}$ (estimated from release tests described in Section 2.7). Fresh porcine eyes from a local slaughterhouse were transported immersed in PBS in an iced bath. Then, intact scleras and corneas with 2-3 mm of surrounding sclera were isolated with the help of a scalpel and tongs, washed with PBS and fitted into vertical diffusion Franz cells. Donor and receptor chambers were filled with carbonate buffer with a $\mathrm{pH}$ of 7.2. The receptor medium $(6 \mathrm{~mL})$ was kept at $37^{\circ} \mathrm{C}$ under gentle 
magnetic stirring (400 rpm). After 30 min equilibration, the buffer of the donor chambers was removed and replaced with resveratrol-loaded discs (soaked in $100 \mu \mathrm{g} / \mathrm{mL}$ resveratrol in ethanol:water 10:90 $\mathrm{v} / \mathrm{v}$ solution for $72 \mathrm{~h}$ at $36^{\circ} \mathrm{C}$ and $180 \mathrm{rpm}$ ) immersed in $2 \mathrm{~mL}$ of $\mathrm{NaCl} 0.9 \%$. The area available for permeation was $0.785 \mathrm{~cm}^{2}$. The donor chambers were covered with parafilm to prevent evaporation and protected from light to avoid resveratrol degradation. At $30 \mathrm{~min}$ and then each hour for $6 \mathrm{~h}, 1 \mathrm{~mL}$ of sample was taken from the receptor chamber and replaced with the same volume of carbonate buffer with a $\mathrm{pH}$ of 7.2, taking care to remove any bubbles from the diffusion cells.

The amount of resveratrol permeated was quantified using a JASCO (Tokyo, Japan) HPLC (AS-4140 Autosampler, PU-4180 Pump, LC-NetII/ADC Interface Box, CO-4060 Column Oven, MD-4010 Photodiode Array Detector), fitted with a C18 column (Waters Symmetry C18, $5 \mu \mathrm{m}, 4.6 \times 250 \mathrm{~mm}$ ) and operated with ChromNAV software (ver. 2.2.8.5, JASCO, Tokyo, Japan). The analysis was done by isocratic elution with a mobile phase of water:methanol (50:50) at $1 \mathrm{~mL} / \mathrm{min}$, at $35{ }^{\circ} \mathrm{C}$ and with a run time of $8 \mathrm{~min}$. The injection volume was $50 \mu \mathrm{L}$ and the UV detector was set at $305 \mathrm{~nm}$. Retention time was $4.6 \mathrm{~min}$. The method was validated using two different calibration curves of resveratrol in methanol:water 50:50 $\mathrm{v} / \mathrm{v}$, one in the $0.05-2 \mu \mathrm{g} / \mathrm{mL}$ range and other in the $1-6 \mu \mathrm{g} / \mathrm{mL}$ range. The detection and quantification limits were calculated from the first calibration curve to be 0.007 and $0.016 \mu \mathrm{g} / \mathrm{mL}$, respectively. This low-range calibration curve included many points for the precise and accurate quantification of resveratrol in the diluted samples.

After $6 \mathrm{~h}$ of assay, aliquots of the donor chambers were collected to quantify the amount of resveratrol remnant. The corneas and scleras were visually inspected to verify that none of them had cracks or modifications and then placed in Falcon ${ }^{\circledR}$ tubes with $3 \mathrm{~mL}$ of ethanol:water $(50: 50 \mathrm{v} / \mathrm{v})$ medium at $37^{\circ} \mathrm{C}$ under agitation. After $24 \mathrm{~h}$, they were sonicated for $99 \mathrm{~min}$ at $37^{\circ} \mathrm{C}$, centrifuged (1000 rpm, $\left.5 \mathrm{~min}, 25^{\circ} \mathrm{C}\right)$, and the supernatant was filtered (Scharlau ${ }^{\circledR}$ Syringe Filter, $0.22 \mu \mathrm{m} 13 \mathrm{~mm}$ PTFE hydrophilic), centrifuged again $\left(14,000 \mathrm{rpm}, 20 \mathrm{~min}, 25^{\circ} \mathrm{C}\right)$ and filtered again to be analyzed by HPLC, as described above.

\subsection{HET-CAM Test}

The Hen's Egg Test on the Chorioallantoic Membrane (HET-CAM) assay was carried out using fertilized hens' eggs (50-60 g, Coren, Spain) after incubation in a climatic chamber (Ineltec CC SR 0150, Barcelona, Spain), as previously described [38]. On the ninth day, a circular cut of $1 \mathrm{~cm}$ in diameter was made on the wider extreme to remove the eggshell. The inner membrane was wetted and removed, and resveratrol-loaded hydrogel discs (as explained above) were placed on the CAM. Solutions of $0.1 \mathrm{~N} \mathrm{NaOH}$ and $0.9 \% \mathrm{NaCl}$ $(300 \mu \mathrm{L})$ were used as positive and negative control, respectively. The vessels of CAM were observed for $5 \mathrm{~min}$ and the time at which hemorrhage (vessels bleeding), vascular lysis (vessels disintegration) or coagulation (denaturalization of intra and extravascular proteins) appeared was recorded. The irritation score (IS) was calculated as previously reported [39].

\subsection{Protein Adsorption}

A quartz crystal microbalance with dissipation (QCM-D, E4 from Q-Sense, Gothenburg, Sweden) was used to study the adsorption of albumin and lysozyme onto selected silicone- and HEMA-based hydrogels (Table 1). As previously described [40], gold-coated quartz crystals (5 MHz) were treated with UV-ozone for $15 \mathrm{~min}$, rinsed with water and dried with nitrogen. The crystals were coated with a layer of polystyrene $(20 \mu \mathrm{L}, 2 \% \mathrm{wt}$ in toluene) by spin coating (2000 rpm, $30 \mathrm{~s}$ ) and $20 \mu \mathrm{L}$ of the correspondent silicone-monomer mixture was deposited over this layer by spin coating (5000 rpm, $30 \mathrm{~s}$ ). The polystyrene film was only applied for silicone-based mixtures since the direct adhesion of these onto the gold surface was poor. For HEMA-based mixtures, the deposition could be done directly on the gold-coated quartz crystals. In both cases, the polymerization was then carried out at $50{ }^{\circ} \mathrm{C}$ for $30 \mathrm{~min}$ and $70{ }^{\circ} \mathrm{C}$ for $1 \mathrm{~h}[41]$. 
The crystals were mounted on the QCM-D cells and the experimental baselines were obtained with the hydrogel films pre-hydrated in SLF. Normalized frequency $(\Delta \mathrm{f} / \mathrm{n}$, where $n$ corresponds to the number of the harmonic) and dissipation $(\Delta \mathrm{D})$ changes for the $1 \mathrm{st}$, $3 \mathrm{rd}, 5 \mathrm{th}, 7 \mathrm{th}, 9$ th and 11th harmonics were registered throughout the experiments. Protein solutions (albumin $0.05 \mathrm{mg} / \mathrm{mL}$ in SLF and lysozyme $1.9 \mathrm{mg} / \mathrm{mL}$ in SLF) were added and remained for approximately $2.5 \mathrm{~h}$ in contact with the crystals. A final rinsing was done with SLF and the monitored signals were left to stabilize for $20 \mathrm{~min}$. The experiments were carried out in quadruplicate at $36{ }^{\circ} \mathrm{C}$. After each assay, the crystals were retrieved by dipping for $5 \mathrm{~s}$ in piranha solution $\left(\mathrm{H}_{2} \mathrm{SO}_{4}: \mathrm{H}_{2} \mathrm{O}_{2}, 7: 3 \mathrm{v} / \mathrm{v}\right)$, followed by washing in a $2 \%(v / v)$ Hellmanex solution and washing two times in DD water under ultrasound for 15 min each. Finally, the crystals were dried using nitrogen flux and stored.

\subsection{Antibiofilm Properties}

Silicone and HEMA hydrogels $\left(1,4,5\right.$ and 6) and Proclear ${ }^{\circledR} 1$ day CLs were tested in triplicate for $6 \mathrm{~h}$ of growth against $\mathrm{P}$. aeruginosa and $48 \mathrm{~h}$ of growth against $\mathrm{S}$. aureus. Bacterial biofilms were grown on hydrated hydrogel pieces immersed in culture medium using a modified Amsterdam Active Attachment (AAA) model [42] assembled with the tested materials (Figure S2 in Supporting Information). Both non-loaded and resveratrol-loaded hydrogels were tested. As controls, bacteria growth on glass coverslips was monitored both in the absence and in the presence of resveratrol in the culture medium. For this, resveratrol solutions in ethanol:water 10:90 $v / v$ previously filtered (Biofil ${ }^{\circledR}$ Syringe Filter, $0.22 \mu \mathrm{m}$ PES membrane) were added to Luria-Bertani Broth (LB) for P. aeruginosa (4, 12 and $250 \mu \mathrm{g} / \mathrm{mL}$ resveratrol final concentration) and Tryptic Soy Broth (TSB-1) for S. aureus $(5,17$ and $250 \mu \mathrm{g} / \mathrm{mL}$ resveratrol final concentration). In any case, the growth medium was diluted less than $5 \%$ with the resveratrol solution.

\subsubsection{Bacterial Strains and Growth Conditions}

S. aureus ATCC25923 (ATCC, Manassas, VA, USA) and P. aeruginosa PAO1 (Lausanne sub-line, donated by M. Cámara, Univ. of Nottingham, Nottingham, UK) biofilm-forming bacteria were routinely cultured at $37^{\circ} \mathrm{C}$ in TSB-1 and LB, respectively. TSB-1 (15 g of TSB and $2.5 \mathrm{~g}$ of $\mathrm{NaCl}$ for $500 \mathrm{~mL}$ ) and $\mathrm{LB}$ ( $5 \mathrm{~g}$ of tryptone, $2.5 \mathrm{~g}$ of yeast extract and $5 \mathrm{~g}$ of $\mathrm{NaCl}$ for $500 \mathrm{~mL}$ ) media were prepared in distilled water. Both culture media were magnetically stirred at $200 \mathrm{rpm}$ until complete dissolution and then autoclaved $\left(121^{\circ} \mathrm{C}, 1 \mathrm{~atm}, 15 \mathrm{~min}\right)$ to avoid contamination.

\subsubsection{Pre-Inocula and Inocula Preparation}

Pre-inocula were prepared by inoculating sterile Erlenmeyer flasks containing culture medium $(10 \mathrm{~mL})$ with a colony of a $24 \mathrm{~h}$ plate of the corresponding biofilm-forming bacterial pathogen. The flasks were incubated at $37^{\circ} \mathrm{C}$ for $12 \mathrm{~h}$ (P. aeruginosa) or $24 \mathrm{~h}$ (S. aureus) at $100 \mathrm{rpm}$. For inocula preparation, the optical density of the pre-inocula was measured after incubation at $600 \mathrm{~nm}$ (UV-Vis spectrophotometer Thermo Scientific Helios Omega) and adjusted to 0.05 (S. aureus) or 0.01 (P. aeruginosa) by dilution with the corresponding culture medium in sterile Falcon ${ }^{\circledR}$ tubes of $50 \mathrm{~mL}$. The pre-inocula were diluted around 400 and 100-fold for P. aeruginosa and S. aureus, respectively. Finally, the inocula were gently homogenized and divided among 12 -well cell culture plates (4 mL per well). All procedures were performed in a biological safety cabinet.

\subsubsection{Amsterdam Active Attachment (AAA) Model Preparation and Pncubation}

The hydrogels were loaded with resveratrol (as explained above), with the only difference being that they were autoclaved $\left(121^{\circ} \mathrm{C}, 1 \mathrm{~atm}, 15 \mathrm{~min}\right)$ and dried for $72 \mathrm{~h}$ at $37^{\circ} \mathrm{C}$ before soaking in the resveratrol solution $\left(7 \mathrm{~mL}, 37^{\circ} \mathrm{C}, 100 \mathrm{rpm}\right)$. The amount loaded was estimated from the difference between the initial and final amount of resveratrol in the solution, calculated from absorbance measurements performed at $305 \mathrm{~nm}$ (as above). 
All loaded hydrogel pieces were carefully placed in the silicone supports of special metallic covers previously autoclaved $\left(121^{\circ} \mathrm{C}, 1 \mathrm{~atm}, 15 \mathrm{~min}\right)$, using a scalpel and tongs, in a biological safety cabinet. Then, the setup was immersed in the 12-well cell culture plates containing $4 \mathrm{~mL}$ of the corresponding culture media and bacteria.

All hydrogels were tested in triplicate and incubated at $37^{\circ} \mathrm{C}$ under static conditions for $6 \mathrm{~h}$ and $48 \mathrm{~h}$ for P. aeruginosa and S. aureus, respectively. The S. aureus medium was changed every $12 \mathrm{~h}$ by moving the models to new cell culture plates previously filled with $4 \mathrm{~mL}$ of fresh TSB-1 per well. In all cases, after each media exchange period, the absorbance of the culture medium was measured at $600 \mathrm{~nm}$ (UV-Vis spectrophotometer Thermo Scientific Helios Omega), to evaluate planktonic bacterial growth. A similar protocol was used to monitor bacteria growth onto glass coverslips when the medium was supplemented with different concentrations of resveratrol.

\subsubsection{Biofilm Susceptibility}

After the incubation period at $37^{\circ} \mathrm{C}$, the viability of the bacterial biofilms was evaluated using a modified MTT assay [43]. Hydrogel pieces were individually placed in sterile tubes containing $3.6 \mathrm{~mL}$ of PBS and then sonicated for $15 \mathrm{~min}$ to separate and homogenize the biofilms. Then, MTT solution $(5 \mathrm{mg} / \mathrm{mL}, 400 \mu \mathrm{L})$ was added to each tube and the tubes were incubated at $37^{\circ} \mathrm{C}$ for $30 \mathrm{~min}$. Half of the MTT-containing PBS medium was removed and replaced with acid isopropanol $(5 \%(v / v) 1 \mathrm{M} \mathrm{HCl}$ in isopropanol). After $5 \mathrm{~s}$ vortexing, aliquots of the medium $(1 \mathrm{~mL})$ were taken and their absorbance measured at $570 \mathrm{~nm}$ (UV-Vis spectrophotometer Thermo Scientific Helios omega). PBS medium treated in the same way was used as blank.

\subsection{Antioxidant Properties}

The antioxidant activity of resveratrol released from Proclear ${ }^{\circledR} 1$ day CLs, HEMA and silicone hydrogels was determined using a modified DPPH assay [44]. The antioxidant activity was proportional to the disappearance of radical 2,2-diphenyl-1-picrylhydrazyl (DPPH•) in the samples by accepting hydrogen from resveratrol, with the corresponding change in color from purple to yellow and decrease in absorption at $517 \mathrm{~nm}$ [45]. HEMAand silicone-hydrogel-dried discs were loaded with resveratrol (as above) and, then, the release was carried out, as described previously, for 12 and $24 \mathrm{~h}$. The antioxidant activities of the loading solution $(100 \mu \mathrm{g} / \mathrm{mL}$ in ethanol:water 10:90 $v / v$ medium $)$ and the freshly prepared release medium ( $\mathrm{NaCl} 0.9 \%$ ) were also quantified. Non-loaded hydrogels in $\mathrm{NaCl}$ $0.9 \%$ were used as controls to confirm that there were no leaching substances that could cause false antioxidant activity during the test. To carry out the test, a $0.1 \mathrm{mM}$ solution of $\mathrm{DPPH} \bullet$ in ethanol was freshly prepared and stored in a flask protected from light. Then, an aliquot of each release medium $(1 \mathrm{~mL})$ was mixed with $1 \mathrm{~mL}$ of DPPH• solution and vortexed for $5 \mathrm{~s}$. After $30 \mathrm{~min}$ of incubation in the dark, the absorbance was measured at $517 \mathrm{~nm}$ (UV-Vis spectrophotometer Agilent 8534, Waldbronn, Germany). The test was carried out at least in triplicate. The DPPH• scavenging capacity was expressed as $\mu \mathrm{g} / \mathrm{mL}$ of DPPH in the reaction medium and calculated from a validated calibration curve of $\mathrm{DPPH} \bullet$ in ethanol $(4-25 \mu \mathrm{g} / \mathrm{mL})$. The DPPH• scavenging effect (\%) was obtained using the following Equation (2), where $A_{C}$ is the absorbance at $517 \mathrm{~nm}$ of the control and $A_{S}$ is the absorbance of the test compound.

$$
\text { DPPH scavenging effect }(\%)=\left(1-\frac{\mathrm{A}_{\mathrm{s}}}{\mathrm{A}_{\mathrm{c}}}\right) \times 100
$$

The results were expressed also as Trolox equivalent antioxidant capacity (TEAC) calculated from a validated calibration curve of Trolox in $\mathrm{NaCl} 0.9 \%(5-35 \mu \mathrm{M})$, processed in the same way as the samples for comparative purposes.

The antioxidant capacity of a resveratrol solution in ethanol:water 10:90 $\mathrm{v} / \mathrm{v}$ medium after being exposed to white light (HITACHI 8 W F8T5 daylight, Chiyoda, Japan) for $3 \mathrm{~h}$ (14 cm gap from the lamp) was also tested. 


\subsection{Statistical Analysis}

The effects of hydrogel composition on swelling, drug loading, permeability through porcine eye tissues and biofilm formation were analyzed using ANOVA and multiple range test (Statgraphics Centurion XVII, StatPoint Technologies Inc., Warrenton VA, USA).

\section{Results and Discussion}

\subsection{Hydrogel Synthesis}

HEMA and silicone hydrogels were designed to combine the features demanded by CLs (water uptake, light transmittance, mechanical properties) while adding antibiofilm capacity, with the aim of attenuating the risk of ocular infections associated with CL wearing $[15,19]$. Two strategies were followed to endow CLs with antibiofilm features: copolymerization with MPC and loading of resveratrol. To the best of our knowledge, resveratrol-eluting CLs have not been previously investigated, although resveratrol may find applications in the ocular field as an antioxidant, anti-inflammatory, antiangiogenic and anticarcinogenic agent $[33,46,47]$. MPC is a component of one commercially available soft (HEMA-based) CL brand (Proclear ${ }^{\circledR}$ ) that claims to retain more water on its surface. MPC is also being tested as a surface component of post-synthesis-modified CLs [14,15]. In the present study, MPC was added as comonomer during the synthesis of the hydrogels. The highest content in MPC was limited by the compatibility of this hydrophilic monomer with the silicone-based mixture. MPC can make the silicone hydrogels whitish due to the microphase separation of silicone and hydrophilic monomers [48], which was indeed evident for S5 and S6 hydrogels (as discussed below). Proclear ${ }^{\circledR} 1$ day CLs are reported to have 3\% MPC [49], which is equivalent to $101 \mathrm{mM}$; therefore, this proportion was chosen as the highest one to be investigated. Hydrogel codes $\mathrm{H} 1, \mathrm{H} 2, \mathrm{H} 3, \mathrm{H} 4, \mathrm{H} 5$ and $\mathrm{H} 6$ in Table 1 correspond to 0, 10, 20, 30, 60 and $101 \mathrm{mM} \mathrm{MPC;} \mathrm{similarly,} \mathrm{S1,} \mathrm{S2,} \mathrm{S3,} \mathrm{S4,} \mathrm{S5} \mathrm{and} \mathrm{S6}$ correspond to $0,10,20,30,80$ and $101 \mathrm{mM}$ MPC.

\subsection{Water Uptake and Wettability}

The water uptake (Table 2 and Figure S3) was higher for silicone hydrogels than for HEMA hydrogels despite the hydrophobic character of TRIS. The addition of hydrophilic monomers, mainly NVP [50,51] and, to a lesser extent, MPC [17], explains the greater water uptake of silicone hydrogels. In fact, the designed silicone hydrogels showed a higher water content than that previously recorded for other silicone hydrogels [48,50], even with a very similar composition [52]. The water uptake of HEMA hydrogels was in good agreement with previously reported values $[34,53]$ and was similar to that obtained for other HEMA hydrogels copolymerized with acrylic acid and 4-vinyl pyridine [54]. The amount of water absorbed for both types of hydrogels slightly increased with the addition of MPC. For a given composition, no significant changes in swelling were observed between water and SLF. Contrastingly, the percentage of swelling was statistically higher $(p<0.05)$ for hydrogels immersed in the resveratrol solution in ethanol:water 10:90 medium due to the presence of ethanol [55]. The highest value of water uptake was observed for Proclear ${ }^{\circledR}$ 1 day CLs.

The hydrogels' surface wettability was determined by measuring the contact angle using the captive bubble method [35]. Compared to the sessile drop method commonly used to characterize rigid gas permeable CLs, the captive bubble method is particularly advantageous for hydrogel materials that may lose water when exposed to air and may deform (swell) when the drop enters into contact with the surface. The captive bubble method is carried out with hydrogel pieces immersed in water (which prevents changes in swelling degree) and, although the recording of the bubble shape can be time-consuming, the measurements are more reliable [35]. The contact angle values were very similar for all compositions, in the range of $37^{\circ}$ to $41^{\circ}$ for HEMA hydrogels and $32^{\circ}$ to $46^{\circ}$ range for silicone ones (Figure S4). It is known that in the dry state, silicone-based hydrogels are more hydrophobic than HEMA-based ones, due to the presence of siloxane groups in the former [52]. However, upon hydration, the silicone-based hydrogel acquired a similar 
hydrophilicity to HEMA, since, in the presence of water (polar solvent), reorientation of the hydrophilic and hydrophobic groups of the chains may occur: the hydrophobic siloxane groups are mainly hidden, and the hydrophilic functionalities of HEMA and NVP become exposed to the surface. Although the addition of MPC led to higher water uptake values in both types of hydrogel, the measurements of water contact angle did not show a significant effect on surface hydrophilicity. This may be due to the small amount of MPC, whose effect is minor when compared to that induced by the other hydrophilic monomers present in the hydrogel matrix. Other authors found a reduction in the water contact angle with an increase in MPC amount, but for hydrogels with MPC grafted to the surface [56,57] or with much higher amounts of MPC [58]. It should be noted that the contact angles obtained for all compositions fell in the range of the values typical of commercial CLs and were similar to the contact angle reported for Proclear ${ }^{\circledR}\left(47.4 \pm 7.5^{\circ}\right)$ [59] using the same technique.

Table 2. Water uptake at equilibrium and Young's modulus (mean values \pm S.D.) for all non-loaded silicone hydrogels (S1-S6) and HEMA hydrogels (H1-H6) immersed in water at room temperature and amounts of resveratrol loaded when the hydrogels were soaked in a resveratrol solution $(100 \mu \mathrm{g} / \mathrm{mL})$ in ethanol:water 10:90 $\mathrm{v} / \mathrm{v}$ medium at $36{ }^{\circ} \mathrm{C}$ and $180 \mathrm{rpm}$ for $72 \mathrm{~h}$ without intermediate measurements.

\begin{tabular}{|c|c|c|c|}
\hline Hydrogel Code & Water Uptake (\%) & Young's Modulus (MPa) & Resveratrol Loaded $(\mu \mathrm{g} / \mathrm{mg})$ \\
\hline S1 & $91.9 \pm 0.6$ & $2.00 \pm 0.07$ & $37.37 \pm 0.68$ \\
\hline S2 & $92.2 \pm 0.5$ & $2.29 \pm 0.17$ & $49.22 \pm 1.74$ \\
\hline S3 & $93.2 \pm 1.1$ & $2.01 \pm 0.37$ & $41.66 \pm 0.96$ \\
\hline S4 & $92.4 \pm 1.5$ & $2.46 \pm 0.09$ & $47.87 \pm 0.72$ \\
\hline S5 & $105.8 \pm 0.9$ & $2.47 \pm 0.09$ & $50.11 \pm 2.06$ \\
\hline S6 & $107.3 \pm 0.9$ & $2.32 \pm 0.21$ & $58.58 \pm 4.05$ \\
\hline H1 & $56.4 \pm 0.5$ & $0.61 \pm 0.03$ & $8.57 \pm 0.56$ \\
\hline $\mathrm{H} 2$ & $57.4 \pm 0.3$ & $0.67 \pm 0.01$ & $8.80 \pm 0.35$ \\
\hline $\mathrm{H} 3$ & $58.4 \pm 0.6$ & $0.68 \pm 0.04$ & $8.32 \pm 0.22$ \\
\hline $\mathrm{H} 4$ & $59.2 \pm 0.1$ & $0.67 \pm 0.05$ & $8.66 \pm 0.53$ \\
\hline H5 & $62.6 \pm 0.8$ & $0.66 \pm 0.01$ & $9.27 \pm 0.75$ \\
\hline H6 & $67.6 \pm 0.1$ & $0.60 \pm 0.01$ & $8.40 \pm 0.09$ \\
\hline Proclear $^{\circledR} 1$ day & $139.9 \pm 2.3$ & $0.44 \pm 0.08$ & $13.59 \pm 0.36$ \\
\hline
\end{tabular}

\subsection{Light Transmission}

Light transmittance of all hydrogel compositions in water, SLF and resveratrol solution (in ethanol:water 10:90 $v / v$ medium) showed values above $90 \%$ in the visible range $(600 \mathrm{~nm})$, except for the S5 and S6 hydrogels, which were slightly opalescent (Figure 2; Figure S5). Although all hydrogels had an apparently smooth surface, SEM images of freeze-dried hydrogels recorded at high magnification evidenced the roughness of S5 and S6 hydrogels, showing islet-like patterns typical of microphase separation (Figure S6) [15]. S4 images were quite similar to those of S1, which suggests that the low MPC content did not trigger phase separation. No significant differences in light transmittance were observed between hydrogels swollen in water, SLF or resveratrol solution, besides the fact that the loading of resveratrol provided very efficient protection against UV radiation (Figure 2E,F). The beneficious UV filter effect had a nondetrimental impact on the light transmission above $400 \mathrm{~nm}$. 

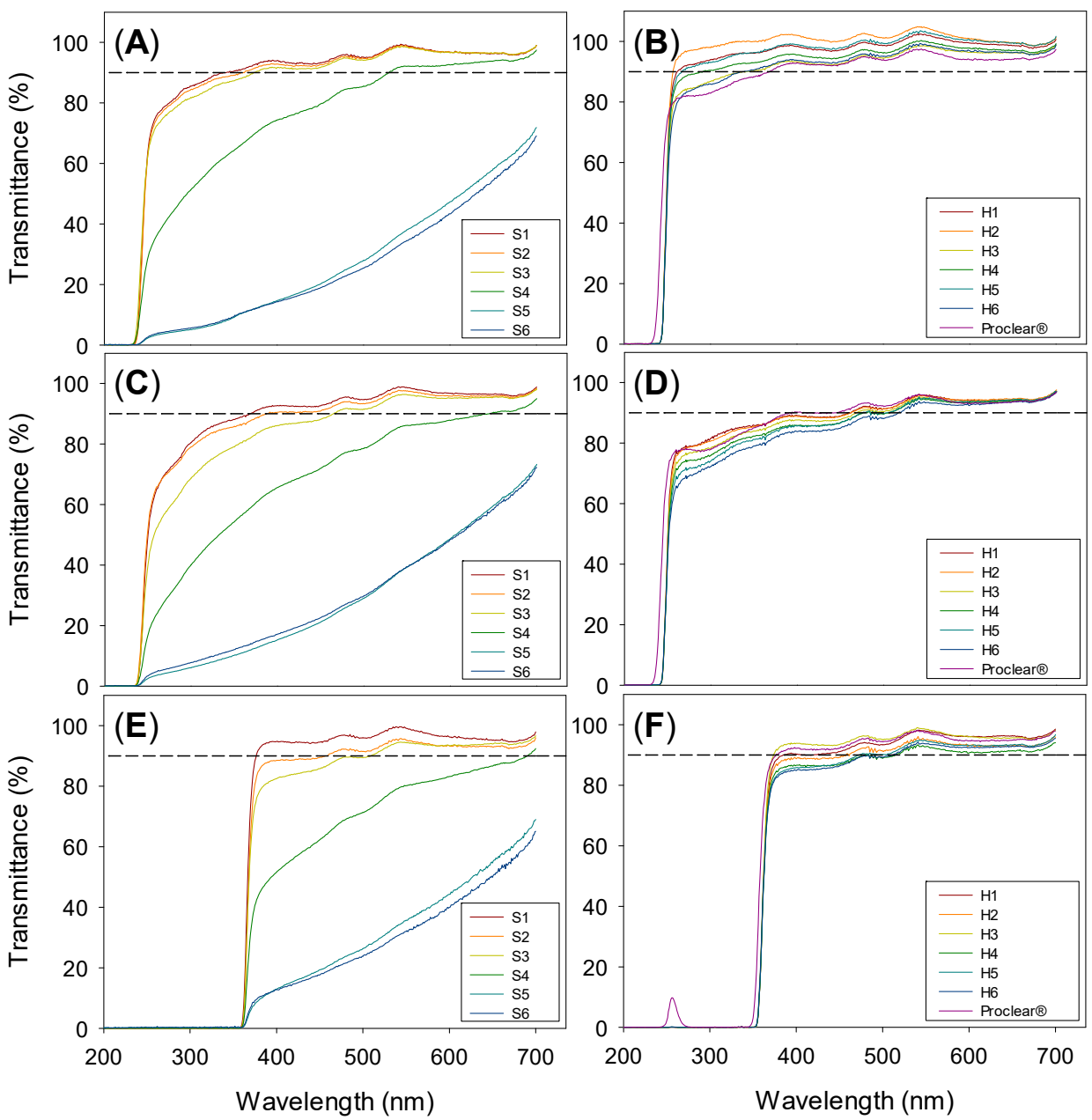

Figure 2. Light transmission of silicone (left) and HEMA (right) hydrogels swollen in water (A,B), SLF (C,D) and resveratrol loading solution (E,F). Dashed lines indicate the acceptance value of $90 \%$ transmittance.

\subsection{Mechanical Properties}

The Young's modulus values of the swollen strips are shown in Table 2 for all hydrogel compositions. Silicone hydrogels had a Young's modulus larger than HEMA hydrogels, in agreement with the behavior reported in the literature [60]. The Young's modulus of the HEMA hydrogels was in the range of those typical of soft contact lenses [58]. The Young's modulus registered for Proclear ${ }^{\circledR} 1$ day CLs matched the value of the data sheet $(0.4 \mathrm{MPa})$. The values recorded for the silicone hydrogels were close to the first-generation silicone hydrogels, although it should be noted that, at the eye temperature, the values may be slightly lower [60]. Interestingly, MPC at the highest proportion investigated only caused a minor decrease (not statistically significant) in the mechanical properties of the CLs, in contrast to the previously reported decrease in Young's moduli observed for HEMA-MPC networks prepared with larger proportions of MPC [58].

\subsection{Resveratrol Loading and Release}

Resveratrol loading was carried out by soaking the hydrogel discs in a resveratrol solution $(100 \mu \mathrm{g} / \mathrm{mL})$ in ethanol:water 10:90 $v / v$ medium until no changes in the absorbance of the loading medium were observed. Loading of the hydrogels during polymerization by the addition of resveratrol to the monomer solution was discarded since the antioxidant power of resveratrol may have hindered the polymerization [37]. All hydrogels were soaked for at least 3 days, but equilibrium was attained in less than $48 \mathrm{~h}$ (Figure 3A,B). Silicone hydrogels captured more than $75 \%$ resveratrol initially present in the loading solution 
(estimated from the difference between resveratrol amount in the loading medium at time 0 and at the end of the test). HEMA hydrogels rapidly sorbed resveratrol, and the final loading corresponded to $\sim 44 \%$ resveratrol available. To monitor the loading, aliquots of the medium were taken for subsequent dilution before absorbance measurements. This caused some loss of resveratrol available for loading. Thus, a second loading study was carried out without intermediate measurements for $72 \mathrm{~h}$; the amount loaded by silicone hydrogels corresponded to more than $80 \%$ resveratrol initially present in the loading solution and to $\sim 50 \%$ for HEMA hydrogels (data shown in Table 2). Compared to the designed HEMA hydrogels, Proclear ${ }^{\circledR} 1$ day CLs showed higher loading, as expressed per unit of weight. The greater surface contact area with the Proclear ${ }^{\circledR} 1$ day CLs (14.2 mm diameter), and the lower thickness (center thickness of $0.09 \mathrm{~mm}$ ) compared to the HEMA hydrogels $(10 \mathrm{~mm}$ diameter, $0.45 \mathrm{~mm}$ thickness), may have contributed to faster and more efficient loading. Nevertheless, the total amount loaded per CL was lower for Proclear ${ }^{\circledR} 1$ day CLs than for the other HEMA hydrogel discs due to the lower weight of the CLs.
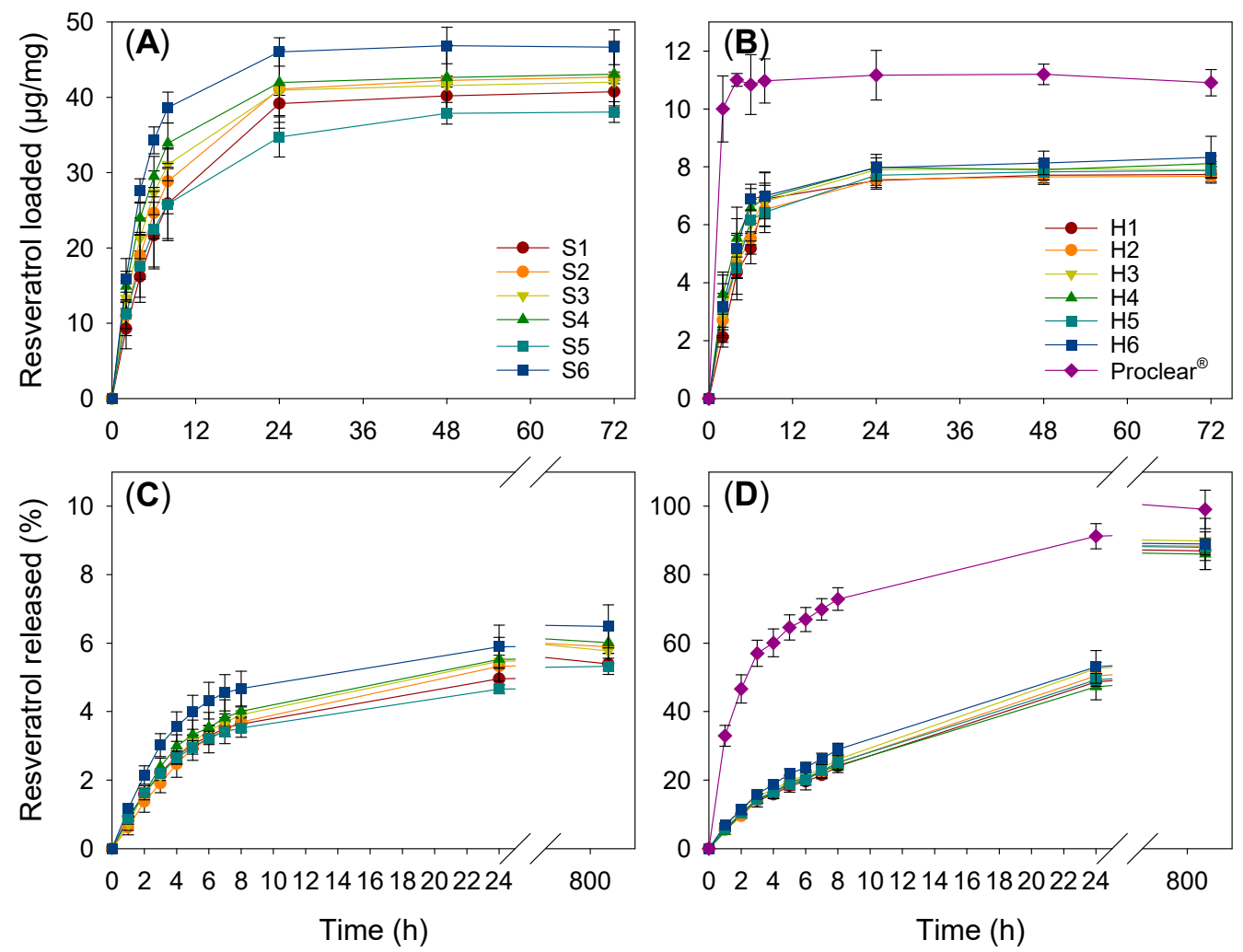

Figure 3. Resveratrol loading profiles for silicone (A) and HEMA (B) based hydrogels at $36{ }^{\circ} \mathrm{C}$ and $180 \mathrm{rpm}$ for $72 \mathrm{~h}$, and release profiles from silicone (C) and HEMA (D)-based hydrogels in $\mathrm{NaCl} 0.9 \%$ medium at $36^{\circ} \mathrm{C}$.

Overall, both types of hydrogel had high affinity for resveratrol, but the network/water partition coefficient for silicone hydrogels ( $\mathrm{K}_{\mathrm{N} / \mathrm{W}}$ in the 373 to 492 range) was four/six-fold higher than that recorded for HEMA hydrogels $\left(\mathrm{K}_{\mathrm{N} / \mathrm{W}}\right.$ in the 77-81 range). Proclear ${ }^{\circledR} 1$ day CLs had $\mathrm{K}_{\mathrm{N} / \mathrm{W}}$ values ( 100) slightly higher than those recorded for HEMA hydrogels. These values are in the range of or even greater than those previously reported for related silicone hydrogels [61] and HEMA hydrogels [62] in the presence of other active ingredients. In any case, the large $\mathrm{K}_{\mathrm{N} / \mathrm{W}}$ values obtained indicated that resveratrol was loaded not only in the aqueous phase of the hydrogel but also interacting with the network [37]. No evident effect of MPC addition on resveratrol loading was found.

Resveratrol release profiles from both types of hydrogel were remarkably different (Figure 3C,D). The test was carried out in Falcon ${ }^{\circledR}$ tubes with a sufficient volume of liquid in order to avoid saturation (resveratrol solubility in $\mathrm{NaCl} 0.9 \%$ was quantified as 27.4 (s.d. 
1.4) $\mu \mathrm{g} / \mathrm{mL}$ ) and under gentle stirring (180 rpm) in order to avoid pseudo-equilibrium and artifact plateaus. Reliable in vitro release methods for drug-loaded CLs that can serve to predict drug release in vivo are still needed [63]. Nevertheless, a requirement that any in vitro method must meet is to avoid the occurrence of false balances between the drug remaining in the contact lens and the drug already delivered, leading to delivery rates much slower than would be expected in vivo.

Silicone hydrogels strongly retained resveratrol and released less than $8 \%$ of the amount loaded in five weeks. Contrastingly, HEMA hydrogels provided sustained release of $33 \%$ load in the first $8 \mathrm{~h}$. The amount of resveratrol released from Proclear ${ }^{\circledR}$ was above $80 \%$ in the first $8 \mathrm{~h}$. In comparison with other similar silicone-based hydrogels that were loaded with chlorhexidine, moxifloxacin and diclofenac [64], the release was slower, and no burst was recorded. This finding suggests more intense hydrophobic interactions between the silicone network and resveratrol.

The amount of resveratrol released was above the minimum required $(2.28 \mu \mathrm{g} / \mathrm{mL})$ in cell cultures to protect retinal pigment epithelial cells from UVA-induced oxidative damage [65] and also to protect retinal pigment epithelial cells against hyperglycemiainduced inflammation and gap junction intercellular communication degradation [66]. Thus far, no resveratrol-loaded CLs have been described in the literature for the ophthalmic administration of resveratrol, and most information relies on its topical ocular [67] and oral administration through food or dietary supplements [68-70]. Although the minimum effective concentration of resveratrol needed in the tear fluid for therapeutic effects is unknown, assuming that the concentration reported above $(2.28 \mu \mathrm{g} / \mathrm{mL})$ is sufficient and considering that the volume of tear produced per day is $4.32 \mathrm{~mL}$ (i.e., $\sim 3 \mu \mathrm{L} / \mathrm{min}$ ), the minimum amount that the CL should supply is $9.84 \mu \mathrm{g}$. Assuming that the weight of a common CL is $13 \mathrm{mg}$, all designed hydrogels can easily provide more resveratrol than the minimum required $(9.84 / 13=0.75 \mu \mathrm{g} / \mathrm{mg})$ after the first $2 \mathrm{~h}$ of wearing, according to the release profiles shown in Figure 3.

Regarding the minor effect of MPC on the resveratrol loading and release results, only formulations prepared without (S1, H1) and with the highest proportions of MPC (S4, S5, $\mathrm{S} 6$ and $\mathrm{H} 4, \mathrm{H} 5$ and $\mathrm{H} 6$ ) were considered for subsequent studies.

\subsection{Resveratrol Stability}

Since trans-resveratrol is quite prone to isomerization and degradation [36], stability studies were carried out to gain an insight into the feasibility of using resveratrol for topical ophthalmic administration. No changes in the UV-Vis spectra of resveratrol in ethanol:water 10:90 $v / v$ medium and in $\mathrm{NaCl} 0.9 \%$ solution were recorded for $24 \mathrm{~h}$ and 10 days, respectively, under the loading and release conditions (dark, $36^{\circ} \mathrm{C}$ and $180 \mathrm{rpm}$ ) (Figure 4A,B). When resveratrol loading solution was exposed to white light for $24 \mathrm{~h}$ (Figure 4C,D), the absorbance at $305 \mathrm{~nm}$ (maximum for trans-resveratrol) decreased, and thus the ratio of absorbance at $286 \mathrm{~nm}$ (maximum of cis-resveratrol) to absorbance at $305 \mathrm{~nm}$ increased, which indicated its transformation into the less active isomer [71]. This phenomenon occurred more slowly when the resveratrol solution was exposed to the usual light conditions of the laboratory (Figure 4D).

To investigate whether the hydrogels could protect resveratrol from light degradation, resveratrol-loaded HEMA- and silicone-based hydrogels (by soaking in ethanol:water solution for $72 \mathrm{~h}$ as in Section 3.5) were removed from the loading medium and directly placed into empty quartz cells and exposed to a white light lamp (HITACHI 8 W F8T5 daylight, Japan) for $3 \mathrm{~h}$ at room temperature. Then, the release profiles were recorded (Figure 5); the UV-Vis patterns were very similar, as well as the amounts released, to those recorded for hydrogels that were not exposed to the white light (Figure 3). This suggested that the hydrogels could protect resveratrol against photodegradation, as later confirmed by the antioxidant tests (Section 3.10). 

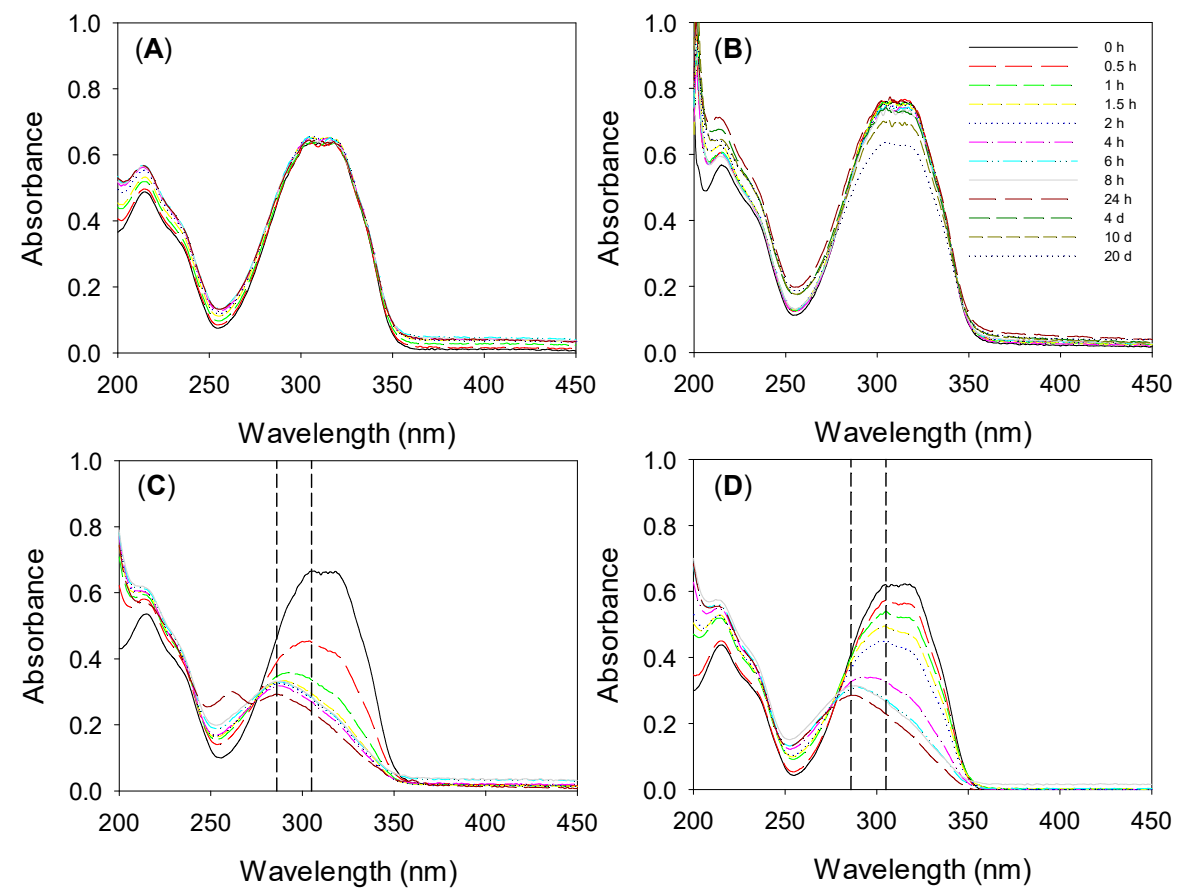

Figure 4. UV-Vis spectra recorded for resveratrol in ethanol:water 10:90 $v / v$ medium (A) and resveratrol in $\mathrm{NaCl} 0.9 \%$ (B) without light at $36^{\circ} \mathrm{C}$ and $180 \mathrm{rpm}$ for several days, and resveratrol in ethanol:water 10:90 $v / v$ medium exposed to white light (C) and working area light (D) for $24 \mathrm{~h}$. Dashed lines indicate the maximum wavelength of cis-resveratrol $(286 \mathrm{~nm})$ and trans-resveratrol $(305 \mathrm{~nm})$.
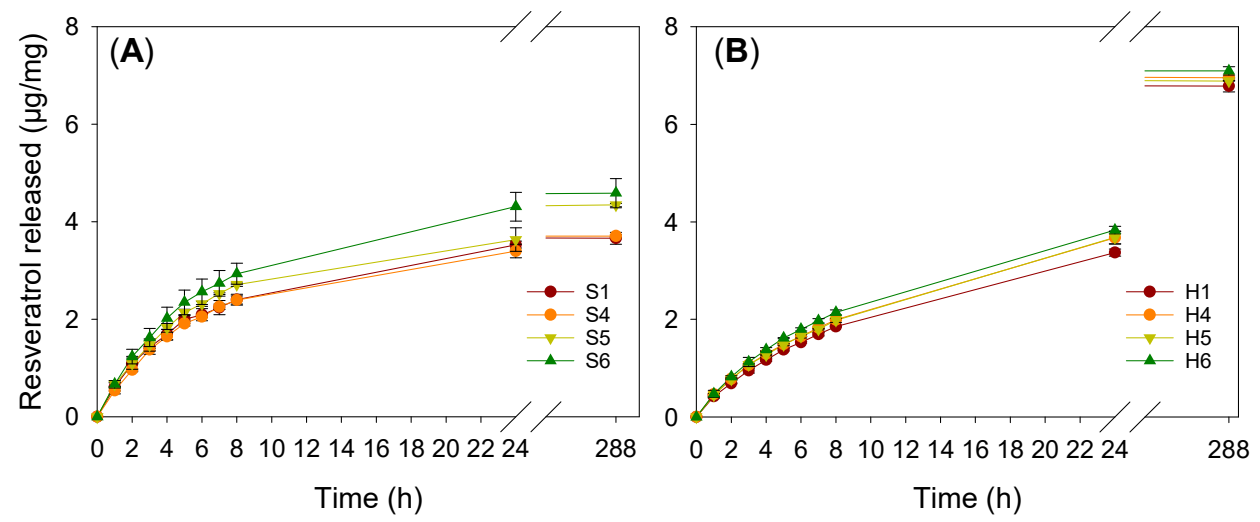

Figure 5. Release profiles of resveratrol in $\mathrm{NaCl} 0.9 \%$ from silicone- (A) and HEMA (B)-based hydrogels. After being loaded with resveratrol, the hydrogels were exposed for $3 \mathrm{~h}$ to white light. The release profiles were constructed considering the absorbance maximum of trans-resveratrol.

\subsection{Corneal and Scleral Permeability}

The permeability and retention capacity of resveratrol released from the most promising hydrogels and Proclear ${ }^{\circledR} 1$ day CLs were investigated using porcine eyes, which are the most similar to human eyes considering the globe size, corneal thickness, ratio of globe diameter to corneal length, presence of Bowman's layer, sclera histology and collagen bundle organization [72]. As a control, a resveratrol concentrated solution $(70 \mu \mathrm{g} / \mathrm{mL}$ in ethanol:water 10:90 $v / v$ medium) was used.

Resveratrol crossed neither the cornea nor the sclera, regardless of whether it was released from the hydrogels or directly applied as a concentrated solution. Resveratrol solubility in $\mathrm{NaCl} 0.9 \%$ was measured to be 27.4 (s.d. 1.6) $\mu \mathrm{g} / \mathrm{mL}$ and the experimental setup ensured that the receptor chamber was not saturated. Therefore, a sufficient concentration gradient could exist between the donor and the receptor chamber. For example, when the concentrated resveratrol solution was tested, the donor chamber contained $1 \mathrm{~mL}$ 
of $70 \mu \mathrm{g} / \mathrm{mL}$ (in ethanol:water 10:90 $\mathrm{v} / \mathrm{v}$ ). Since the volume of receptor medium was $6 \mathrm{~mL}$, if all resveratrol could pass to the receptor (assuming no adsorption to the cornea or sclera), the maximum concentration that could be reached in the receptor would be $10 \mu \mathrm{g} / \mathrm{mL}$. Therefore, the absence of resveratrol in the receptor chamber cannot be attributed to low solubility in the receptor medium. In the $6 \mathrm{~h}$ time frame of the study, measurable amounts of resveratrol in the receptor chamber were not recorded in any case. Contrastingly, resveratrol accumulated in the cornea and sclera tissue (Figure 6A). Accumulation was higher in the sclera than in the cornea for all formulations. The highest amount accumulated was recorded for the resveratrol solution $\left(24.5 \pm 1.2\right.$ and $21.6 \pm 0.8 \mu \mathrm{g} / \mathrm{cm}^{2}$ for sclera and cornea, respectively). This finding clearly correlated with the lower resveratrol levels that the hydrogel formulations can provide to the donor chamber, as shown in Figure 6B. In good agreement with the release profiles shown in Figure 3, HEMA hydrogels provided more resveratrol to the donor chamber than silicone hydrogels.
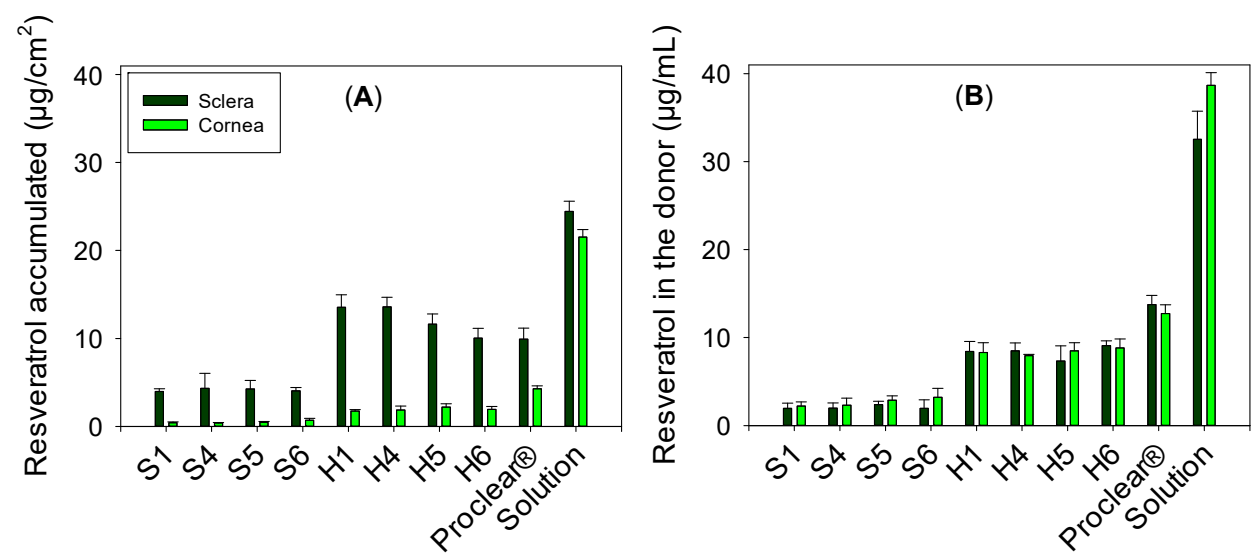

Figure 6. Amounts of resveratrol accumulated in cornea and sclera (A) and remaining in the donor chamber (B) when delivered as resveratrol-loaded silicone and HEMA hydrogels, and Proclear ${ }^{\circledR}$ contact lenses, or as resveratrol solution $(70 \mu \mathrm{g} / \mathrm{mL})$.

Differences in silicone hydrogel composition did not cause any change in the amount of resveratrol accumulated in the cornea or sclera (no statistically significant differences for a given tissue). For $\mathrm{H} 1$ and $\mathrm{H} 4$ hydrogels, the amount of resveratrol accumulated in the sclera $\left(13.6 \pm 1.4\right.$ and $\left.13.6 \pm 1.1 \mu \mathrm{g} / \mathrm{cm}^{2}\right)$ was statistically higher than for $\mathrm{H} 6$ and Proclear ${ }^{\circledR}$ $\left(10.1 \pm 1.1\right.$ and $\left.9.9 \pm 1.2 \mu \mathrm{g} / \mathrm{cm}^{2}\right)$. Regarding cornea tests, the amount of resveratrol accumulated was, surprisingly, higher for Proclear ${ }^{\circledR}$ CLs, which may be related to the faster release provided by these CLs. Interestingly, the amounts of resveratrol accumulated in the cornea and sclera once released from HEMA hydrogels were remarkably higher than those previously reported for the antioxidant transferulic acid [37].

\subsection{HET-CAM Test}

The Hen's Egg Test on the Chorioallantoic Membrane (HET-CAM) assay was used to gain an insight into the compatibility of the developed hydrogels with the ocular surface. The vasculature of the CAM of fertilized eggs is comparable to the conjunctiva structure [39]. All hydrogel compositions could be considered non-irritating because none of them caused hemorrhage, vascular lysis or coagulation of CAM vessels during the $5 \mathrm{~min}$ of the test (Figure S7) [62]. The IS registered for the positive control was 19.4.

\subsection{Protein Adsorption}

The adsorption of albumin and lysozyme, as two of the major proteins present in the tear fluid, was evaluated using a QCM-D. Changes in the values of frequency $(\Delta \mathrm{f} / \mathrm{n})$ and dissipation $(\Delta \mathrm{D})$ are shown in Figures S8-S11 (Supporting Information) and summarized in Table 3 for the third harmonic. 
Table 3. Frequency $(\Delta f / n)$ and dissipation $(\Delta D)$ variations for the 3rd harmonic for albumin and lysozyme adsorption onto silicone and HEMA hydrogels, obtained by QCM-D. Estimated values for mass variation $(\Delta \mathrm{m})$ and layer thickness $\left(\mathrm{d}_{\mathrm{eff}}\right)$ are also presented (average \pm standard deviation, $\left.n=4\right)$.

\begin{tabular}{cccccc}
\hline Hydrogel & Protein & $\boldsymbol{\Delta} \mathbf{f} / \mathbf{n}(\mathbf{H z})$ & $\boldsymbol{\Delta D}\left(\times \mathbf{1 0}^{-\mathbf{6}}\right)$ & $\boldsymbol{\Delta \mathbf { m }} \mathbf{( \mathbf { n g } / \mathbf { c m } ^ { \mathbf { 2 } } )}$ & $\mathbf{d}_{\text {eff }}(\mathbf{n m})$ \\
\hline S1 & & $-15.5 \pm 4.1$ & $0.9 \pm 0.6$ & $275 \pm 72$ & $2.4 \pm 0.6$ \\
S4 & Albumin & $-7.0 \pm 1.5$ & $0.9 \pm 1.1$ & $124 \pm 27$ & $1.1 \pm 0.2$ \\
S5 & $-4.3 \pm 0.5$ & $-0.2 \pm 0.6$ & $77 \pm 9$ & $0.6 \pm 0.1$ \\
S6 & & $-3.8 \pm 0.8$ & $-0.9 \pm 0.4$ & $68 \pm 15$ & $0.5 \pm 0.1$ \\
\hline S1 & & $-31.8 \pm 6.3$ & $0.4 \pm 0.6$ & $562 \pm 110$ & $4.1 \pm 0.8$ \\
S4 & Lysozyme & $-31.0 \pm 3.4$ & $0.6 \pm 0.2$ & $548 \pm 60$ & $4.0 \pm 0.4$ \\
S5 & & $-24.1 \pm 7.8$ & $0.1 \pm 0.1$ & $427 \pm 140$ & $3.1 \pm 1.0$ \\
S6 & & $-21.3 \pm 0.6$ & $0.9 \pm 0.5$ & $377 \pm 11$ & $2.7 \pm 0.1$ \\
\hline H1 & & $-15.6 \pm 6.4$ & $0.6 \pm 0.3$ & $275 \pm 114$ & $2.4 \pm 1.0$ \\
H4 & Albumin & $-14.1 \pm 5.4$ & $0.1 \pm 1.1$ & $250 \pm 96$ & $2.2 \pm 0.8$ \\
H5 & & $-8.5 \pm 1.7$ & $0.9 \pm 0.1$ & $150 \pm 30$ & $1.5 \pm 0.4$ \\
H6 & & $-29.4 \pm 0.8$ & $0.1 \pm 0.9$ & $114 \pm 15$ & $1.0 \pm 0.1$ \\
\hline H1 & & $-24.0 \pm 7.3$ & $0.1 \pm 0.5$ & $424 \pm 129$ & $3.7 \pm 0.6$ \\
H4 & Lysozyme & $-19.5 \pm 2.2$ & $1.4 \pm 0.6$ & $345 \pm 39$ & $2.5 \pm 0.3$ \\
H5 & & $-8.5 \pm 2.4$ & $1.8 \pm 1.5$ & $151 \pm 43$ & $1.1 \pm 0.3$ \\
H6 & & & &
\end{tabular}

The addition of lysozyme and albumin led to a decrease in frequency in all cases, demonstrating that both proteins adsorbed onto the surfaces. The decrease in frequency was more accentuated in the case of lysozyme, independently of the nature of the hydrogel (silicon-based or HEMA-based), indicating that a higher amount of protein adsorbed onto the hydrogel's surface. In all cases, the adsorption was attenuated with the increase in the MPC amount in the hydrogels, which confirmed the capacity of MPC to avoid protein adsorption [73]. This effect was more pronounced for lysozyme on HEMA-based hydrogels.

The degree of overlapping of the curves $\Delta \mathrm{f} / \mathrm{n}$ versus time obtained for the different harmonics was analyzed to predict the viscoelastic character of the adsorbed film. The obtained graphics presented a high degree of overlapping, indicating that the protein adsorbed layers showed high stiffness. The rigid nature of the formed films was confirmed by the low values of $\Delta \mathrm{D}$, which indicates that a low amount of energy was dissipated.

For rigid films, the variation in frequency $(\Delta \mathrm{f} / \mathrm{n})$ is proportional to the mass of the adsorbed film $(\Delta \mathrm{m})$ according to the Sauerbrey Equation (3):

$$
\Delta \mathrm{m}=-\mathrm{C} \times \frac{\Delta \mathrm{f}}{\mathrm{n}}
$$

where $\mathrm{C}$ is the sensitivity constant based on the physical properties of the quartz crystal ( $\mathrm{C}=17.7 \mathrm{ng} \mathrm{cm}^{-2} \mathrm{~Hz}^{-1}$ for a $5 \mathrm{MHz}$ crystal) [74,75]. Additionally, the thickness ( $\left.\mathrm{d}_{\mathrm{eff}}\right)$ of the adhering films can be estimated through Equation (4), considering $1.15 \mathrm{~g} / \mathrm{cm}^{3}$ [75] and $1.38 \mathrm{~g} / \mathrm{cm}^{3}$ [76] as the density of albumin and lysozyme films [77]:

$$
\mathrm{d}_{\mathrm{eff}}=\frac{\Delta \mathrm{m}}{\rho_{\text {eff }}}
$$

Overall, MPC demonstrated a significant antifouling effect for both proteins: for the hydrogels with the highest value of MPC, lower thickness and $\Delta \mathrm{m}$ values were obtained. This is in agreement with previous studies that found that the existence of zwitterionic MPC moieties on the surfaces of the HEMA- and silicone-based hydrogels decreased the adsorption of proteins, such as lysozyme, fibrinogen and albumin [56-58]. This protein repulsion capacity was attributed to the high hydration of the phosphorylcholine groups present on MPC $[56,58]$. It is known that the increase in the ratio of MPC increases the amount of free water but decreases that of bound water [78]. Therefore, when a protein 
comes into contact with the hydrogel surface, it may remain in this native state, not altering its structure. This facilitates the release of loosely bound protein molecules, leading to a decrease in protein adsorption.

The differences between the adsorbed amounts of albumin and lysozyme may be related to the size, shape, charge, conformational stability of the proteins and their concentration in the adsorbing solution. Protein adsorption is a complex phenomenon, and the weight of the different contributions is difficult to identify. Albumin is a large, anionic, soft protein (MW $66.4 \mathrm{kDa}$ ) with a heart shape $(8 \mathrm{~mm}$ side $\times 3 \mathrm{~nm}$ thickness) while lysozyme is a small, ellipsoid, cationic, hard protein (MW $14.7 \mathrm{kDa}$ ) with axes of $2.6 \mathrm{~nm}$ and $4.5 \mathrm{~nm}$ [79]. In this work, different concentrations of each protein were used to perform the adsorption experiments $(0.05 \mathrm{mg} / \mathrm{mL}$ for albumin and $1.9 \mathrm{mg} / \mathrm{mL}$ for lysozyme). Both conformational and concentration differences may explain the lower amount of adsorbed albumin on the hydrogels.

The inhibitory effect of MPC on protein adsorption was less evident for lysozyme on silicon-based hydrogels, which may be due to the stronger interactions between the protein and the surface. In fact, the hydrogel surface should be negatively charged (high affinity to positive polyelectrolytes was previously found [80]), enhancing the binding to the positively charged protein. Such a preferential binding of lysozyme on MPC-containing hydrogels may readily occur after placement on the eye's surface [81], which may contribute to the antimicrobial performance [82].

\subsection{Antibiofilm Properties}

First, the susceptibility to soluble resveratrol of the two main causal agents of ocular infections, S. aureus and P. aeruginosa [5], was evaluated by quantifying the effect of different concentrations of resveratrol on bacteria growth and biofilm formation on inert glass surfaces. P. aeruginosa biofilm formation on the surface of the coverslips immersed in growth medium supplemented with resveratrol was lower than without resveratrol (Figure 7A), although the differences were not statistically significant for the two lower concentrations tested ( 4 and $12 \mu \mathrm{g} / \mathrm{mL}$ ). The biofilm formation significantly decreased for a $250 \mu \mathrm{g} / \mathrm{mL}$ resveratrol solution, showing the capacity of resveratrol to inhibit biofilm formation against P. aeruginosa and also to prevent the growth of planktonic bacteria (Figure 7C). These findings agree well with previous reports on Resveramax ${ }^{\mathrm{TM}}$ (oily alimentary supplement) that evidenced that resveratrol was active against $P$. aeruginosa PAO1 biofilm $[26,83]$. In contrast, the biofilm formation after $48 \mathrm{~h}$ of growth of $S$. aureus (Figure 7B) was higher for $5 \mu \mathrm{g} / \mathrm{mL}$ of resveratrol than for the controls, but the biofilm was completely inhibited when the resveratrol concentration was raised to $250 \mu \mathrm{g} / \mathrm{mL}$. The bacterial growth in the medium surrounding the coverslips was in good agreement with the absorbances recorded for the surfaces (Figure 7D). The increase in biofilm formation observed at low resveratrol concentrations for S. aureus may be the result of a stress response of the cells in the presence of sub-inhibitory concentrations of this compound, since the slower growth of bacteria in the biofilm may have had a protective effect against resveratrol. An increase in biofilm formation as a response to the cell stress caused by antimicrobial agents has been described before [84].

In all cases, it should be noted that the MTT assay used to evaluate the biofilm formation determines mitochondrial activity since it is based on the conversion of MTT into formazan crystals by living cells and not only biofilm biomass or cell number, being therefore a highly sensitive method [85]. Resveratrol has been suggested to alter the MTT reduction rate in mammalian cell cultures, not because of a direct effect on MTT reduction but through an indirect effect on cell metabolism [86]. Such an effect is of small magnitude and has not been reported for bacteria. 

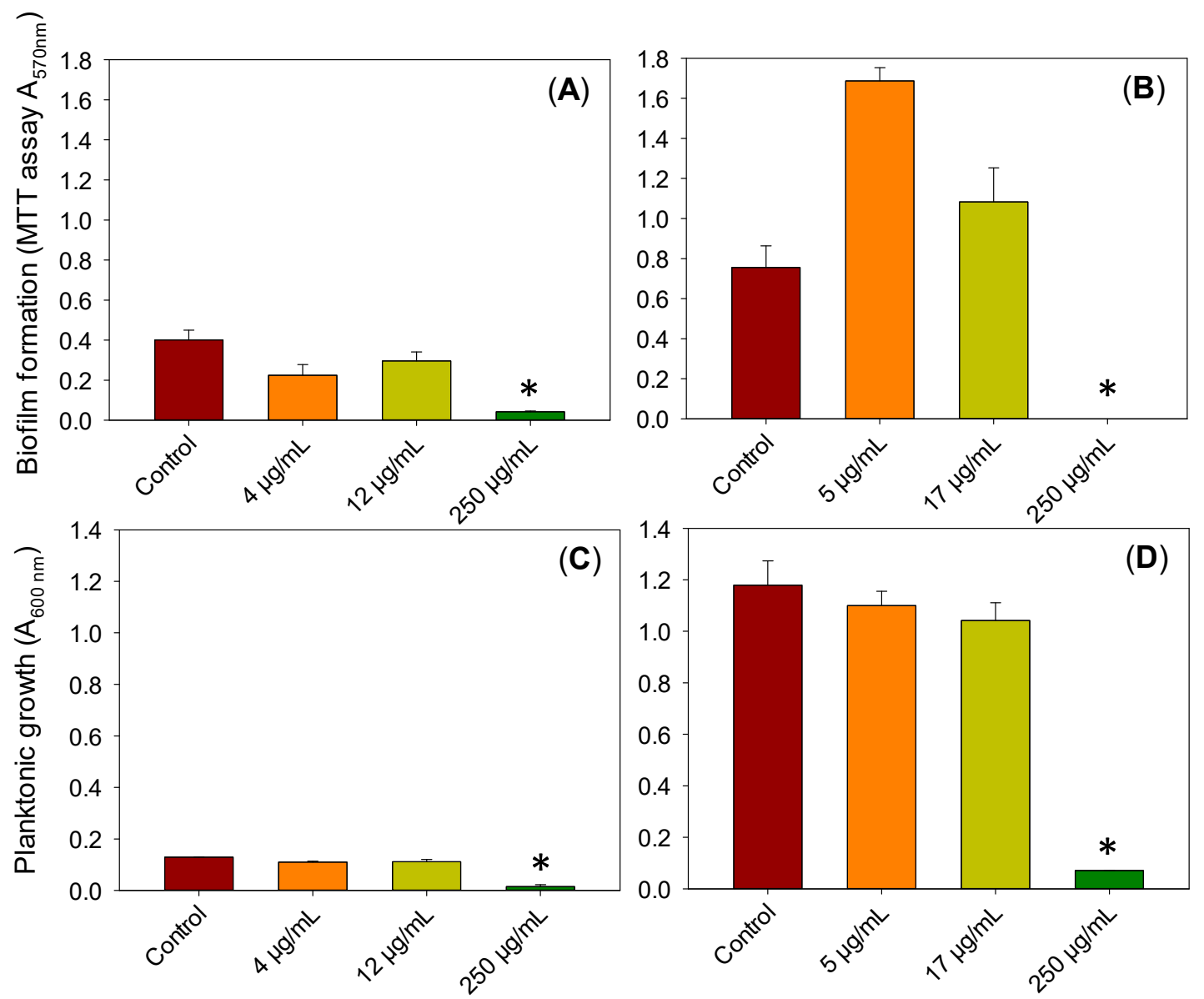

Figure 7. Growth of Pseudomonas aeruginosa (A,C) and Staphylococcus aureus (B,D) biofilm on the surface of glass coverslips measured with the MTT assay $(\mathbf{A}, \mathbf{B})$ and in the culture medium surrounding the coverslips (C,D), to which resveratrol at different concentrations was added. * indicates a statistically significant difference with respect to the control without resveratrol $(p<0.05)$.

Next, the antibiofilm performance of silicone and HEMA hydrogels with and without MPC in their composition and loaded or not with resveratrol was investigated. In the case of $P$. aeruginosa, more biofilm was formed on the hydrogels without resveratrol (Figure 8A,B) compared to those loaded with resveratrol. No differences were recorded for Proclear ${ }^{\circledR} 1$ day CLs with and without resveratrol, which may be related to the fact that the amount loaded per lens was the lowest (see Table 2). In HEMA hydrogels, the inhibitory effect of the resveratrol loading was more evident, probably due to the greater amounts released. The absorbance of the supernatants was also measured (Figure 8C,D) and the planktonic bacterial growth was very similar in the culture media around the hydrogels loaded or not with resveratrol. Notably, although the biofilm formation was clearly lower in the resveratrol-loaded HEMA hydrogels than in their respective unloaded controls (Figure $8 \mathrm{~B}$ ), planktonic growth was generally higher in the presence of resveratrolloaded lenses (Figure 8D), indicating the specific antibiofilm activity of the compound for P. aeruginosa.

In the case of $S$. aureus, the biofilm formation after $48 \mathrm{~h}$ of incubation (Figure 9A,B) for all hydrogels was lower than for P. aeruginosa despite the much higher bacterial growth in the medium surrounding the hydrogels (Figure 9C,D). For all HEMA- and silicone-based hydrogels, the biofilm formation was almost the same and no statistically significant differences were observed with the addition of MPC and/or resveratrol. This finding agreed with two other studies where resveratrol did not reduce biofilm formation and confirms that strain variation and assay conditions may influence the efficacy $[87,88]$. Unexpectedly, no remarkable antibiofilm effect could be assigned to MPC, which could be related to the 
fact that, in the designed hydrogels, the MPC monomer was copolymerized during the synthesis process and not added later as a surface modification process, as commonly reported in the literature [89]. Therefore, MPC is expected to be evenly distributed in the bulk of the hydrogel and not confined to the surface. This may have caused the density of MPC chains on the surface to be insufficient to prevent bacteria adhesion.
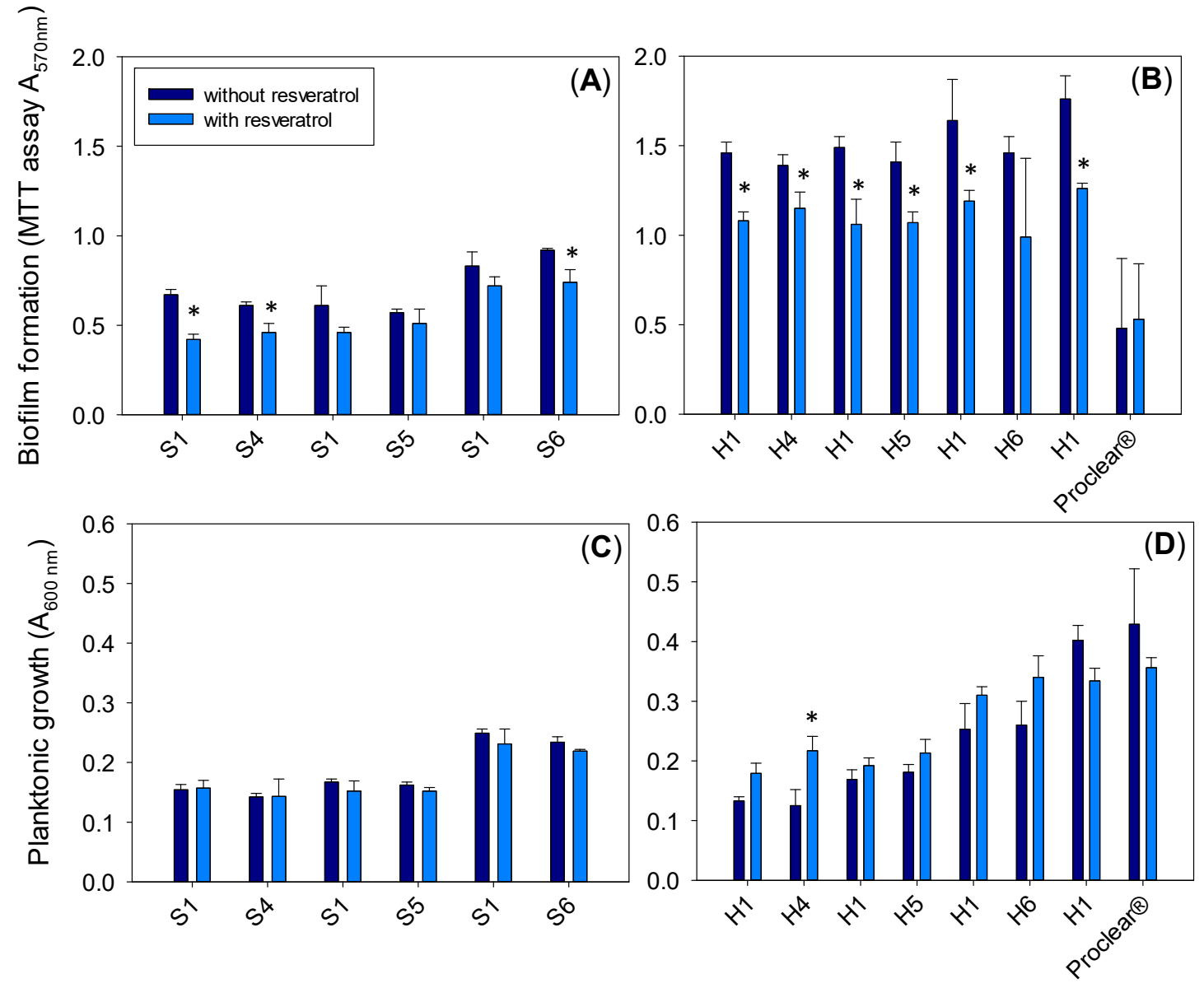

Figure 8. Growth of Pseudomonas aeruginosa PAO1 biofilm on the surfaces of silicone (A) and HEMA (B) hydrogels (without and with resveratrol) measured with the MTT assay, and in the culture medium surrounding the silicone (C) and HEMA (D) hydrogels (without and with resveratrol) after $6 \mathrm{~h}$ of incubation. * indicates a statistically significant difference between hydrogels with and without resveratrol $(p<0.05)$. In each experiment, a silicone hydrogel prepared with MPC (S4, S5 and S6) was evaluated in parallel to the silicone hydrogel without MPC (S1). Similarly, the HEMA hydrogels prepared with MPC (H4, H5 and H6) were evaluated in parallel to the HEMA hydrogel without MPC (H1).

The adhesion of bacteria is usually higher on hydrophobic hydrogels than on hydrophilic ones [3,90-92]. Here, the biofilm formation for both bacteria was lower for silicone hydrogels. Although the wettability of the silicone- and HEMA-based hydrogels was not significantly different, the lower biofilm formation could be related to the higher water uptake observed for silicone hydrogels due to the presence of hydrophilic monomers (mainly NVP), as explained above. 

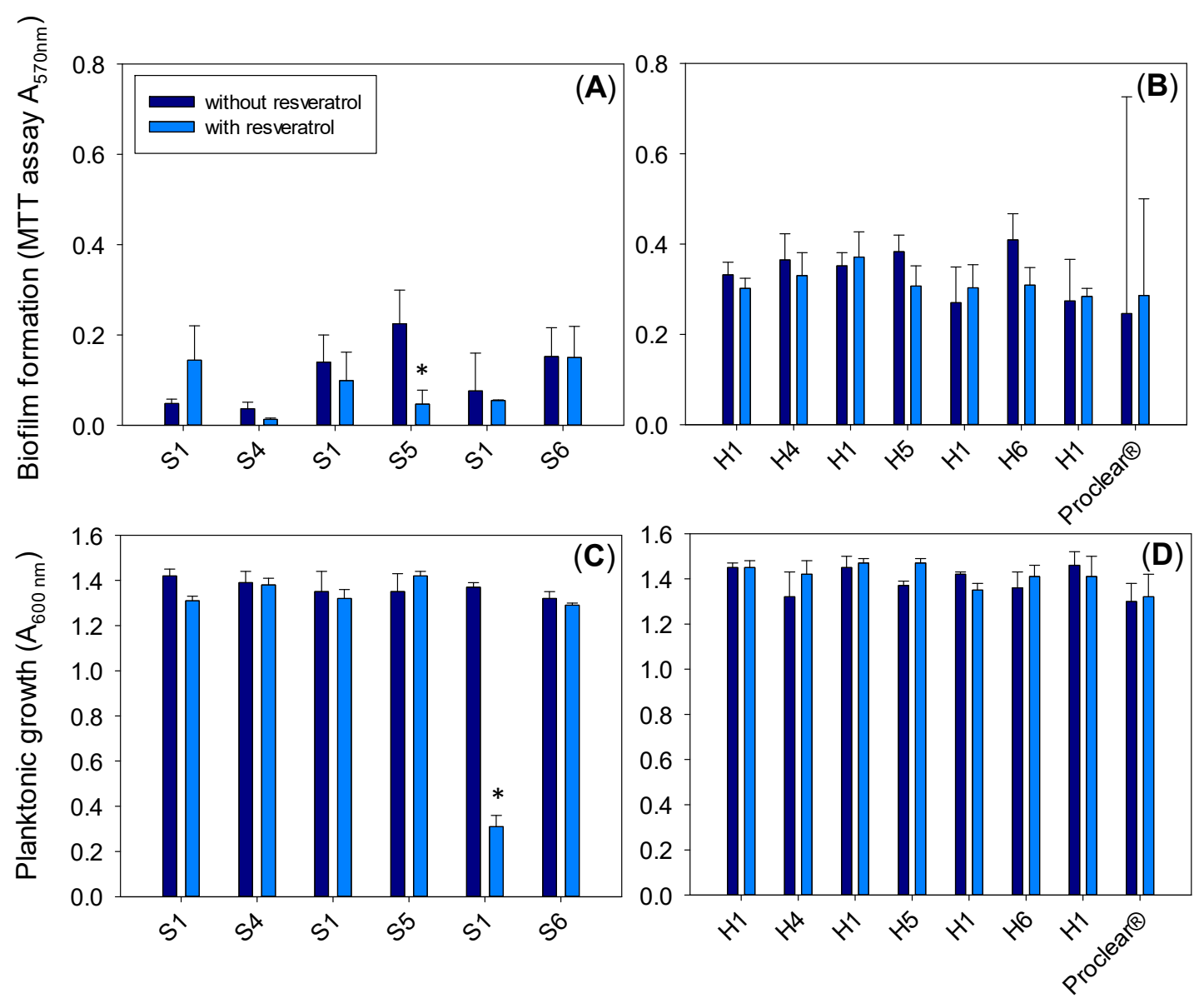

Figure 9. Growth of Staphylococcus aureus biofilm on the surface of silicone (A) and HEMA (B) hydrogels (without and with resveratrol) and in the medium surrounding the silicone (C) and HEMA (D) hydrogels (without and with resveratrol) after $48 \mathrm{~h}$ of incubation. In each experiment, a silicone hydrogel prepared with MPC (S4, S5 and S6) was evaluated in parallel to the silicone hydrogel without MPC (S1). Similarly, the HEMA hydrogels prepared with MPC (H4, H5 and H6) were evaluated in parallel to the HEMA hydrogel without MPC (H1). * indicates a statistically significant difference between hydrogels with and without resveratrol $(p<0.05)$.

\subsection{Antioxidant Properties}

The DPPH assay was used to check whether resveratrol maintained its antioxidant activity after being loaded and released from HEMA and silicone hydrogels. Freshly prepared $\mathrm{NaCl} 0.9 \%$ release medium, as well as $\mathrm{NaCl} 0.9 \%$ solutions in which non-loaded hydrogels were soaked, were also tested to verify that there were no leaching substances that could cause false antioxidant activity during the assay. The DPPH• scavenging capacity was expressed as $\mu \mathrm{g} / \mathrm{mL}$ in the reaction medium, as a percentage, as explained previously [44], and as Trolox equivalent antioxidant capacity (TEAC) for comparative purposes. Analysis of freshly prepared resveratrol loading solution led to $3.5 \pm 1.2 \mu \mathrm{g} / \mathrm{mL}$ DPPH levels and $40.5 \pm 2.8 \mu \mathrm{M}$ TEAC. Samples from the release tests are expected to cover a wide range of resveratrol concentrations (according to Figures 3 and 5) but well below the concentration of the loading solution.

According to the results (Table 4, Figures S12-S14), the levels of DPPH• radicals registered for $\mathrm{NaCl} 0.9 \%$ medium without resveratrol $(20.1 \mu \mathrm{g} / \mathrm{mL})$ were higher than for the release medium of the resveratrol-loaded hydrogels. This finding indicates that the released resveratrol maintained its capacity to reduce the free radicals and thus retained its antioxidant activity after being loaded and released from the HEMA and silicone hydrogels. At the same time, the effect registered was very similar within the same type of hydrogel, but antioxidant capability was higher for HEMA than for silicone hydrogels, as expected, 
since HEMA hydrogels released higher amounts of resveratrol into the medium. Nonloaded hydrogels showed values of TEAC that were close to zero or even negative, meaning that they did not release any substance that may have interfered with the test.

Table 4. DPPH• levels $(\mu \mathrm{g} / \mathrm{mL})$, DPPH scavenging effect $(\%)$ and Trolox equivalent antioxidant capacity (TEAC). All data are mean $\pm \operatorname{SDs}(n=3)$.

\begin{tabular}{|c|c|c|c|c|c|c|}
\hline \multirow[t]{2}{*}{ Hydrogels } & \multicolumn{2}{|c|}{ DPPH• $(\mu \mathrm{g} / \mathrm{mL})$} & \multicolumn{2}{|c|}{$\begin{array}{c}\text { DPPH• Scavenging } \\
\text { Effect }(\%)\end{array}$} & \multicolumn{2}{|c|}{ TEAC $(\mu \mathrm{M})$} \\
\hline & $12 \mathrm{~h}$ & $24 \mathrm{~h}$ & $12 \mathrm{~h}$ & $24 \mathrm{~h}$ & $12 \mathrm{~h}$ & $24 \mathrm{~h}$ \\
\hline S1 & $15.6 \pm 0.2$ & 14. $8 \pm 0.9$ & $26.1 \pm 1.1$ & $29.0 \pm 4.3$ & $10.6 \pm 0.5$ & $12.6 \pm 2.2$ \\
\hline S2 & $16.3 \pm 2.3$ & $13.4 \pm 0.6$ & $27.8 \pm 2.4$ & $41.8 \pm 2.6$ & $8.9 \pm 5.6$ & $15.9 \pm 1.4$ \\
\hline S3 & $15.6 \pm 0.6$ & $14.2 \pm 0.3$ & $38.7 \pm 2.6$ & $27.6 \pm 1.5$ & $10.5 \pm 1.6$ & $14.0 \pm 0.7$ \\
\hline S4 & $15.7 \pm 2.1$ & $13.2 \pm 0.3$ & $30.3 \pm 9.6$ & $33.4 \pm 1.7$ & $10.3 \pm 5.2$ & $16.5 \pm 0.8$ \\
\hline S5 & $15.1 \pm 1.3$ & $13.2 \pm 0.7$ & $35.5 \pm 5.7$ & $45.3 \pm 3.1$ & $11.8 \pm 3.2$ & $16.5 \pm 1.8$ \\
\hline S6 & $14.6 \pm 0.9$ & $13.6 \pm 1.7$ & $26.0 \pm 4.9$ & $36.8 \pm 7.9$ & $13.1 \pm 2.3$ & $15.6 \pm 4.1$ \\
\hline $\mathrm{H} 1$ & $11.5 \pm 0.1$ & $10.0 \pm 1.0$ & $44.0 \pm 0.7$ & $51.6 \pm 4.9$ & $20.5 \pm 0.3$ & $24.4 \pm 2.4$ \\
\hline $\mathrm{H} 2$ & $12.1 \pm 0.8$ & $11.9 \pm 2.1$ & $39.1 \pm 4.3$ & $40.2 \pm 11.0$ & $19.2 \pm 2.0$ & $19.6 \pm 5.3$ \\
\hline H3 & $13.0 \pm 0.9$ & $11.6 \pm 1.7$ & $36.4 \pm 4.4$ & $42.0 \pm 8.8$ & $17.0 \pm 2.2$ & $20.5 \pm 4.2$ \\
\hline $\mathrm{H} 4$ & $12.2 \pm 0.4$ & $10.8 \pm 0.7$ & $41.7 \pm 2.0$ & $47.7 \pm 3.3$ & $19.1 \pm 1.0$ & $22.3 \pm 1.6$ \\
\hline H5 & $11.3 \pm 0.5$ & $12.1 \pm 3.6$ & $48.1 \pm 2.4$ & $38.4 \pm 18.9$ & $21.3 \pm 1.2$ & $19.2 \pm 8.9$ \\
\hline H6 & $11.3 \pm 0.8$ & $9.8 \pm 0.5$ & $44.0 \pm 4.1$ & $58.9 \pm 2.1$ & $21.1 \pm 2.0$ & $24.9 \pm 1.2$ \\
\hline Proclear $^{\circledR}$ & $11.0 \pm 0.4$ & $11.1 \pm 1.4$ & $47.5 \pm 2.0$ & $46.5 \pm 7.0$ & $22.0 \pm 1.0$ & $21.6 \pm 3.5$ \\
\hline
\end{tabular}

The antioxidant capacity of resveratrol solutions after being exposed to white light (HITACHI $8 \mathrm{~W}$ F8T5 daylight, Japan) for $3 \mathrm{~h}$ was confirmed despite isomerization from trans to cis $(13.2 \pm 0.03 \mu \mathrm{g} / \mathrm{mL}$ DPPH levels, and $16.37 \pm 0.07 \mu \mathrm{M}$ TEAC). Overall, both HEMA and silicone hydrogels helped resveratrol to maintain its antioxidant activity, which may be useful in managing ocular diseases that benefit from a decrease in reactive oxygen species (ROS) levels.

\section{Conclusions}

The use of MPC as a comonomer of HEMA- and silicone-based hydrogels and their loading with resveratrol have been studied here for first time to obtain hydrogels with antioxidant and antibiofilm properties. MPC increased the water uptake and decreased the amount of protein adsorbed while preserving the mechanical properties of the hydrogels. Only silicone hydrogels prepared with the highest proportions of MPC investigated (80 and $101 \mathrm{mM}$ ) evidenced a decrease in light transmission. All hydrogels were able to uptake relevant amounts of resveratrol. The higher affinity of silicone hydrogels for resveratrol, probably due to hydrophobic interactions, notably increased the amount loaded but also caused the release to occur more slowly. As a consequence, the amounts of resveratrol accumulated in the cornea and sclera were lower when delivered from the silicone hydrogels. Regarding the antibiofilm activity, resveratrol decreased biofilm formation by P. aeruginosa, but no protective effect was recorded for MPC against the two strains investigated. Nevertheless, the fact that the hydrogels prepared with MPC showed preferential sorption of lysozyme with respect to albumin may contribute to the antibacterial effects in vivo, which should be evaluated in future studies. The inconclusive antibiofilm performance of the hydrogels on $S$. aureus suggests that the loading should be increased in order to achieve an inhibitory concentration. Importantly, HEMA- and silicone-based hydrogels preserved the antioxidant activity of resveratrol and showed a protective effect against photodegradation. Overall, hydrogels containing MPC and loaded with resveratrol are demonstrated to be suitable candidates for the preparation of CLs with antibiofilm and antioxidant performance. 
Supplementary Materials: The following are available online at https: / www.mdpi.com/article/ 10.3390 / pharmaceutics13040532/s1. Figure S1: Image of a bubble adhered to a hydrogel contact lens when the captive bubble method was used for the measurement of the water contact angle $(\theta)$; Figure S2: Amsterdam Active Attachment model assembled with the tested hydrogel pieces; Figure S3: Water uptake (\%) of silicone and HEMA hydrogels in water, SLF and resveratrol loading solution; Figure S4: Water contact angles on the silicone-based hydrogels and HEMA-based hydrogels; Figure S5: Reading test for silicone and HEMA hydrogels; Figure S6: SEM images of freeze-dried hydrogels recorded at high magnification $(50,000 \times)$; Figure S7: Images of the HET-CAM test; Figures S8-S11: Normalized shift in the frequency, $\Delta \mathrm{f} / \mathrm{n}$, and shift in the dissipation, $\Delta \mathrm{D}$, for the third harmonic of the resonant frequency of quartz crystal sensors coated with S1, S4, S5, S6, H1, H4, H5 and H6 hydrogel films after addition of albumin or lysozyme; Figure S12: Antioxidant activity of resveratrol released from silicone hydrogels and their respective controls; Figure S13: Antioxidant activity of resveratrol released from HEMA hydrogels and their respective controls; Figure S14: Antioxidant activity of a $100 \mu \mathrm{g} / \mathrm{mL}$ resveratrol in ethanol:water 10:90 $v / v$ solution, $\mathrm{NaCl}$ $0.9 \%$ and DPPH $0.1 \mathrm{mM}$ solution.

Author Contributions: Conceptualization, A.C., C.A.-L., M.V.-L.; methodology, M.V.-L., A.M., D.S.; validation, C.A.-L., A.P.S., A.O.; resources, A.C., C.A.-L., A.P.S., A.O.; writing-original draft preparation, C.A.-L., M.V.-L., A.M.; writing-review and editing, A.C., C.A.-L., A.P.S., A.O.; supervision, C.A.-L., A.C.; project administration, C.A.-L.; funding acquisition, C.A.-L., A.C. All authors have read and agreed to the published version of the manuscript.

Funding: This research was funded by MINECO (SAF2017-83118-R), Agencia Estatal de Investigación (AEI) Spain, Xunta de Galicia (ED431C 2020/17), FEDER, and Fundação para a Ciência e Tecnologia (FCT) Portugal (UIDB/00100/2020 and UIDB/04585/2020). M. Vivero-Lopez acknowledges Xunta de Galicia (Consellería de Cultura, Educación e Ordenación Universitaria) for a predoctoral research fellowship (ED481A-2019/120). The authors acknowledge Ana F. Pereira-da-Mota for help with cornea and sclera permeability tests.

Institutional Review Board Statement: Not applicable. The approval by an ethics committee is not required for the HET-CAM assay since the use of chicken embryos during the first two-thirds of their development is not considered an animal experiment.

Informed Consent Statement: Not applicable.

Data Availability Statement: Raw data is available upon request.

Conflicts of Interest: The authors declare no conflict of interest. The funders had no role in the design of the study; in the collection, analyses, or interpretation of data; in the writing of the manuscript, or in the decision to publish the results.

\section{References}

1. Fleiszig, S.M.J.; Kroken, A.R.; Nieto, V.; Grosser, M.R.; Wan, S.J.; Metruccio, M.M.E.; Evans, D.J. Contact lens-related corneal infection: Intrinsic resistance and its compromise. Prog. Retin. Eye Res. 2020, 76, 100804. [CrossRef] [PubMed]

2. Wiley, L.; Bridge, D.R.; Wiley, L.A.; Odom, J.V.; Elliott, T.; Olson, J.C. Bacterial biofilm diversity in contact lens-related disease: Emerging role of Achromobacter, Stenotrophomonas, and Delftia. Investig. Ophthalmol. Vis. Sci. 2012, 53, 3896-3905. [CrossRef]

3. Dutta, D.; Willcox, M.D. Antimicrobial contact lenses and lens cases: A review. Eye Contact Lens 2014, 40, 312-324. [CrossRef] [PubMed]

4. Arshad, M.; Carnt, N.; Tan, J.; Ekkeshis, I.; Stapleton, F. Water exposure and the risk of contact lens-related disease. Cornea 2019, 38, 791-797. [CrossRef] [PubMed]

5. Bispo, P.J.; Haas, W.; Gilmore, M.S. Biofilms in infections of the eye. Pathogens 2015, 4, 111-136. [CrossRef]

6. El-Ganiny, A.M.; Shaker, G.H.; Aboelazm, A.A.; El-Dash, H.A. Prevention of bacterial biofilm formation on soft contact lenses using natural compounds. J. Ophthal. Inflamm. Infect. 2017, 7, 11. [CrossRef]

7. Robertson, D.M. The effects of silicone hydrogel lens wear on the corneal epithelium and risk for microbial keratitis. Eye Contact Lens 2013, 39, 67. [CrossRef]

8. Zegans, M.E.; Shanks, R.M.; O'toole, G.A. Bacterial biofilms and ocular infections. Ocul. Surf. 2005, 3, 73-80. [CrossRef]

9. Filipe, H.P.; Bozukova, D.; Pimenta, A.; Vieira, A.P.; Oliveira, A.S.; Galante, R.; Topete, A.; Masson, M.; Alves, P.; Coimbra, P.; et al. Moxifloxacin-loaded acrylic intraocular lenses: In vitro and in vivo performance. J. Cataract. Refract. Surg. 2019, 45, 1808-1817. [CrossRef] [PubMed]

10. Khan, S.A.; Lee, C.S. Recent progress and strategies to develop antimicrobial contact lenses and lens cases for different types of microbial keratitis. Acta Biomater. 2020, 113, 101-118. [CrossRef] 
11. Wang, J.; Li, X. Enhancing protein resistance of hydrogels based on poly (2-hydroxyethyl methacrylate) and poly (2methacryloyloxyethyl phosphorylcholine) with interpenetrating network structure. J. Appl. Polym. Sci. 2011, 121, 3347-3352. [CrossRef]

12. Wang, B.; Ye, Z.; Tang, Y.; Han, Y.; Lin, Q.; Liu, H.; Chen, H.; Nan, K. Fabrication of nonfouling, bactericidal, and bacteria corpse release multifunctional surface through surface-initiated RAFT polymerization. Int. J. Nanomed. 2017, 12, 111. [CrossRef]

13. Tan, X.; Zhan, J.; Zhu, Y.; Cao, J.; Wang, L.; Liu, S.; Wang, Y.; Liu, Z.; Qin, Y.; Wu, M.; et al. Improvement of uveal and capsular biocompatibility of hydrophobic acrylic intraocular lens by surface grafting with 2-methacryloyloxyethyl phosphorylcholinemethacrylic acid copolymer. Sci. Rep. 2017, 7, 1-13. [CrossRef] [PubMed]

14. Li, L.; Xin, Z. Surface-hydrophilic and protein-resistant tris (trimethylsiloxy)-3-methacryloxypropylsilane-containing polymer by the introduction of phosphorylcholine groups. Colloid Surf. A Physicochem. Eng. Asp. 2011, 384, 713-719. [CrossRef]

15. Shimizu, T.; Goda, T.; Minoura, N.; Takai, M.; Ishihara, K. Super-hydrophilic silicone hydrogels with interpenetrating poly(2methacryloyloxyethyl phosphorylcholine) networks. Biomaterials 2010, 31, 3274-3280. [CrossRef]

16. Zhang, N.; Zhang, K.; Melo, M.A.S.; Chen, C.; Fouad, A.F.; Bai, Y.; Xu, H.H. Novel protein-repellent and biofilm-repellent orthodontic cement containing 2-methacryloyloxyethyl phosphorylcholine. J. Biomed. Mater. Res. B 2016, 104, 949-959. [CrossRef] [PubMed]

17. Goda, T.; Ishihara, K. Soft contact lens biomaterials from bioinspired phospholipid polymers. Expert Rev. Med. Devices 2006, 3, 167-174. [CrossRef]

18. Huang, X.D.; Yao, K.; Zhang, Z.; Zhang, Y.; Wang, Y. Uveal and capsular biocompatibility of an intraocular lens with a hydrophilic anterior surface and a hydrophobic posterior surface. J. Cataract. Refract. Surg. 2010, 36, 290-298. [CrossRef]

19. Xu, L.; Ma, P.; Yuan, B.; Chen, Q.; Lin, S.; Chen, X.; Hua, Z.; Shen, J. Anti-biofouling contact lenses bearing surface-immobilized layers of zwitterionic polymer by one-step modification. RSC Adv. 2014, 4, 15030-15035. [CrossRef]

20. Huang, X.D.; Yao, K.; Zhang, H.; Huang, X.J.; Xu, Z.K. Surface modification of silicone intraocular lens by 2-methacryloyloxyethyl phosphoryl-choline binding to reduce Staphylococcus epidermidis adherence. Clin. Exp. Ophthalmol. 2007, 35, 462-467. [CrossRef]

21. Bostanghadiri, N.; Pormohammad, A.; Chirani, A.S.; Pouriran, R.; Erfanimanesh, S.; Hashemi, A. Comprehensive review on the antimicrobial potency of the plant polyphenol Resveratrol. Biomed. Pharm. 2017, 95, 1588-1595. [CrossRef] [PubMed]

22. Natesan, S.; Pandian, S.; Ponnusamy, C.; Palanichamy, R.; Muthusamy, S.; Kandasamy, R. Co-encapsulated resveratrol and quercetin in chitosan and PEG modified chitosan nanoparticles: For efficient intra ocular pressure reduction. Int. J. Biol. Macromol. 2017, 104, 1837-1845. [CrossRef] [PubMed]

23. Dinte, E.; Vostinaru, O.; Samoila, O.; Sevastre, B.; Bodoki, E. Ophthalmic nanosystems with antioxidants for the prevention and treatment of eye diseases. Coatings 2020, 10, 36. [CrossRef]

24. Augustine, N.; Goel, A.K.; Sivakumar, K.C.; Kumar, R.A.; Thomas, S. Resveratrol-a potential inhibitor of biofilm formation in Vibrio cholerae. Phytomedicine 2014, 21, 286-289. [CrossRef] [PubMed]

25. Qin, N.; Tan, X.; Jiao, Y.; Liu, L.; Zhao, W.; Yang, S.; Jia, A. RNA-Seq-based transcriptome analysis of methicillin-resistant Staphylococcus aureus biofilm inhibition by ursolic acid and resveratrol. Sci. Rep. 2014, 4, 1-9. [CrossRef]

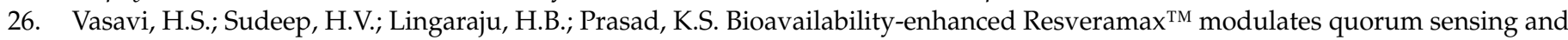
inhibits biofilm formation in Pseudomonas aeruginosa PAO1. Microb. Pathog. 2017, 104, 64-71. [CrossRef]

27. Zhou, J.W.; Chen, T.T.; Tan, X.J.; Sheng, J.Y.; Jia, A.Q. Can the quorum sensing inhibitor resveratrol function as an aminoglycoside antibiotic accelerant against Pseudomonas aeruginosa? Int. J. Antimicrob. Agents 2018, 52, 35-41. [CrossRef]

28. Richter, K.; Van den Driessche, F.; Coenye, T. Innovative approaches to treat Staphylococcus aureus biofilm-related infections. Antimicrob. Resist. 2017, 61, 61-70.

29. Muras, A.; Otero, A. Breaking bad: Understanding how bacterial communication regulates biofilm-related oral diseases. In Trend in Quorum Sensing and Quorum Quenching: New Perspectives and Applications; Rai, V.R., Bai, A.J., Eds.; CRC Press: Boca Raton, FL, USA, 2020; pp. 175-185.

30. Subramanian, M.; Goswami, M.; Chakraborty, S.; Jawali, N. Resveratrol induced inhibition of Escherichia coli proceeds via membrane oxidation and independent of diffusible reactive oxygen species generation. Redox Biol. 2014, 2, 865-872. [CrossRef]

31. Nøhr-Meldgaard, K.; Ovsepian, A.; Ingmer, H.; Vestergaard, M. Resveratrol enhances the efficacy of aminoglycosides against Staphylococcus aureus. Int. J. Antimicrob. Agents 2018, 52, 390-396. [CrossRef]

32. Paulo, L.; Ferreira, S.; Gallardo, E.; Queiroz, J.A.; Domingues, F. Antimicrobial activity and effects of resveratrol on human pathogenic bacteria. World J. Microb. Biotechnol. 2010, 26, 1533-1538. [CrossRef]

33. Bhatt, P.; Fnu, G.; Bhatia, D.; Shahid, A.; Sutariya, V. Nanodelivery of resveratrol-loaded PLGA nanoparticles for age-related macular degeneration. AAPS PharmSciTech 2020, 21, 291. [CrossRef]

34. Alvarez-Rivera, F.; Serro, A.P.; Silva, D.; Concheiro, A.; Alvarez-Lorenzo, C. Hydrogels for diabetic eyes: Naltrexone loading, release profiles and cornea penetration. Mater. Sci. Eng. C 2019, 105, 110092. [CrossRef]

35. Sanchez, I.; Carmona, F.J.; Gonzalez-Puertas, S.; Valiente, A.; Martin, R. Intrasession repeatability of the contact angle measured using the captive bubble method and agreement assessed between different analysis software programs. Eye Contact Lens 2020, 46, 385-390. [CrossRef]

36. Zupančič, Š.; Lavrič, Z.; Kristl, J. Stability and solubility of trans-resveratrol are strongly influenced by $\mathrm{pH}$ and temperature. Eur. J. Pharm. Biopharm. 2015, 93, 196-204. [CrossRef] 
37. Varela-Garcia, A.; Concheiro, A.; Alvarez-Lorenzo, C. Cytosine-functionalized bioinspired hydrogels for ocular delivery of antioxidant transferulic acid. Biomater. Sci. 2020, 8, 1171-1180. [CrossRef]

38. Alvarez-Rivera, F.; Fernández-Villanueva, D.; Concheiro, A.; Alvarez-Lorenzo, C. $\alpha$-Lipoic acid in Soluplus ${ }^{\circledR}$ polymeric nanomicelles for ocular treatment of diabetes-associated corneal diseases. J. Pharm. Sci. 2016, 105, 2855-2863. [CrossRef] [PubMed]

39. ICCVAM. ICCVAM Test Method Evaluation Report: Current Validation Status of In Vitro Test Methods Proposed for Identifying Eye Injury Hazard Potential of Chemicals and Products; NIH Publication No. 10-7553; Research Triangle Park, National Institute of Environmental Health Sciences: Durham, NC, USA, 2010; p. 1324.

40. Silva, D.; Pinto, L.F.; Bozukova, D.; Santos, L.F.; Serro, A.P.; Saramago, B. Chitosan/alginate based multilayers to control drug release from ophthalmic lens. Colloid Surf. B 2016, 147, 81-89. [CrossRef] [PubMed]

41. Teichroeb, J.H.; Forrest, J.A.; Jones, L.W.; Chan, J.; Dalton, K. Quartz crystal microbalance study of protein adsorption kinetics on poly (2-hydroxyethyl methacrylate). J. Colloid Interface Sci. 2008, 325, 157-164. [CrossRef] [PubMed]

42. Mayer, C.; Muras, A.; Romero, M.; López, M.; Tomás, M.; Otero, A. Multiple quorum quenching enzymes are active in the nosocomial pathogen Acinetobacter baumannii ATCC17978. Front. Cell. Infect. Microbiol. 2018, 8, 310. [CrossRef] [PubMed]

43. Vivero-Lopez, M.; Xu, X.; Muras, A.; Otero, A.; Concheiro, A.; Gaisford, S.; Basit, A.W.; Alvarez-Lorenzo, C.; Goyanes, A. Anti-biofilm multi drug-loaded 3d printed hearing aids. Mater. Sci. Eng. C 2020, 119, 111606. [CrossRef]

44. Gülçin, İ. Antioxidant properties of resveratrol: A structure-activity insight. Innov. Food Sci. Emerg. Technol. 2010, 11, 210-218. [CrossRef]

45. Moon, J.K.; Shibamoto, T. Antioxidant assays for plant and food components. J. Agric. Food Chem. 2009, 57, 1655-1666. [CrossRef]

46. Chen, Y.; Meng, J.; Li, H.; Wei, H.; Bi, F.; Liu, S.; Tang, K.; Guo, H.; Liu, W. Resveratrol exhibits an effect on attenuating retina inflammatory condition and damage of diabetic retinopathy via PON1. Exp. Eye Res. 2019, 181, 356-366. [CrossRef]

47. Lançon, A.; Frazzi, R.; Latruffe, N. Anti-oxidant, anti-inflammatory and anti-angiogenic properties of resveratrol in ocular diseases. Molecules 2016, 21, 304. [CrossRef] [PubMed]

48. Nicolson, P.C.; Vogt, J. Soft contact lens polymers: An evolution. Biomaterials 2001, 22, 3273-3283. [CrossRef]

49. Liu, Y. Polymerizable Contact Lens Formulations and Contact Lenses Obtained Therefrom. U.S. Patent No. 8,011,784, 6 September 2011.

50. Tran, N.P.D.; Yang, M.C. Synthesis and characterization of silicone contact lenses based on TRIS-DMA-NVP-HEMA hydrogels. Polymers 2019, 11, 944. [CrossRef] [PubMed]

51. Chien, H.W.; Kuo, C.J. Preparation, material properties and antimicrobial efficacy of silicone hydrogel by modulating silicone and hydrophilic monomer. J. Biomater. Sci. Polym. Ed. 2019, 30, 1050-1067. [CrossRef] [PubMed]

52. Paradiso, P.; Galante, R.; Santos, L.; Alves de Matos, A.P.; Colaço, R.; Serro, A.P.; Saramago, B. Comparison of two hydrogel formulations for drug release in ophthalmic lenses. J. Biomed. Mater. Res. B Appl. Biomater. 2014, 102, 1170-1180. [CrossRef]

53. Dos Santos, J.F.R.; Alvarez-Lorenzo, C.; Silva, M.; Balsa, L.; Couceiro, J.; Torres-Labandeira, J.J.; Concheiro, A. Soft contact lenses functionalized with pendant cyclodextrins for controlled drug delivery. Biomaterials 2009, 30, 1348-1355. [CrossRef]

54. Alvarez-Lorenzo, C.; Yanez, F.; Barreiro-Iglesias, R.; Concheiro, A. Imprinted soft contact lenses as norfloxacin delivery systems. J. Control. Release 2006, 113, 236-244. [CrossRef]

55. Sekar, P.; Dixon, P.J.; Chauhan, A. Pigmented contact lenses for managing ocular disorders. Int. J. Pharm. 2019, 555, 184-197. [CrossRef]

56. Wang, J.J.; Liu, F. Photoinduced graft polymerization of 2-methacryloyloxyethyl phosphorylcholine on silicone hydrogels for reducing protein adsorption. J. Mater. Sci. Mater. Med. 2011, 22, 2651-2657. [CrossRef] [PubMed]

57. Vales Pegarro, T.; Jee, J.-P.; Young Lee, W.; Cho, S.; Lee Myung, G.; Kim, H.-J.; Suk Kim, J. Development of poly(2methacryloyloxyethyl phosphorylcholine)-functionalized hydrogels for reducing protein and bacterial adsorption. Materials 2020, 13, 943. [CrossRef] [PubMed]

58. Chang, W.H.; Liu, P.Y.; Lu, C.J.; Lin, D.E.; Lin, M.H.; Jiang, Y.T.; Hsu, Y.H.H. Reduction of physical strength and enhancement of anti-protein and anti-lipid adsorption abilities of contact lenses by adding 2-methacryloyloxyethyl phosphorylcholine. Macromol. Res. 2020, 28, 1064-1073. [CrossRef]

59. Lin, M.C.; Svitova, T.F. Contact lenses wettability in vitro: Effect of surface-active ingredients. Optom. Vis. Sci. 2010, 87, 440. [CrossRef] [PubMed]

60. Horst, C.R.; Brodland, B.; Jones, L.W.; Brodland, G.W. Measuring the modulus of silicone hydrogel contact lenses. Optom. Vis. Sci. 2012, 89, 1468-1476. [CrossRef]

61. Pimenta, A.F.R.; Ascenso, J.; Fernandes, J.C.S.; Colaço, R.; Serro, A.P.; Saramago, B. Controlled drug release from hydrogels for contact lenses: Drug partitioning and diffusion. Int. J. Pharm. 2016, 515, 467-475. [CrossRef]

62. Alvarez-Rivera, F.; Concheiro, A.; Alvarez-Lorenzo, C. Epalrestat-loaded silicone hydrogels as contact lenses to address diabeticeye complications. Eur. J. Pharm. Biopharm. 2018, 122, 126-136. [CrossRef] [PubMed]

63. Tieppo, A.; Boggs, A.C.; Pourjavad, P.; Byrne, M.E. Analysis of release kinetics of ocular therapeutics from drug releasing contact lenses: Best methods and practices to advance the field. Cont. Lens Anterior Eye 2014, 37, 305-313. [CrossRef] [PubMed]

64. Silva, D.; de Sousa, H.C.; Gil, M.H.; Santos, L.F.; Moutinho, G.M.; Serro, A.P.; Saramago, B. Antibacterial layer-by-layer coatings to control drug release from soft contact lenses material. Int. J. Pharm. 2018, 553, 186-200. [CrossRef]

65. Chan, C.M.; Huang, C.H.; Li, H.J.; Hsiao, C.Y.; Su, C.C.; Lee, P.L.; Hung, C.F. Protective effects of resveratrol against UVA-induced damage in ARPE19 cells. Int. J. Mol. Sci. 2015, 16, 5789-5802. [CrossRef] 
66. Losso, J.N.; Truax, R.E.; Richard, G. Trans-resveratrol inhibits hyperglycemia-induced inflammation and connexin downregulation in retinal pigment epithelial cells. J. Agric. Food Chem. 2010, 58, 8246-8252. [CrossRef] [PubMed]

67. Abengózar-Vela, A.; Schaumburg, C.S.; Stern, M.E.; Calonge, M.; Enríquez-de-Salamanca, A.; González-García, M.J. Topical quercetin and resveratrol protect the ocular surface in experimental dry eye disease. Ocul. Immunol. Inflamm. 2019, 27, 1023-1032. [CrossRef] [PubMed]

68. Abu-Amero, K.K.; Kondkar, A.A.; Chalam, K.V. Resveratrol and ophthalmic diseases. Nutrients 2016, 8, 200. [CrossRef]

69. Goutham, G.; Manikandan, R.; Beulaja, M.; Thiagarajan, R.; Arulvasu, C.; Arumugam, M.; Setzer, W.N.; Daglia, M.; Nabavi, S.F. A focus on resveratrol and ocular problems, especially cataract: From chemistry to medical uses and clinical relevance. Biomed. Pharmacother. 2017, 86, 232-241. [CrossRef]

70. Wang, S.; Wang, Z.; Yang, S.; Yin, T.; Zhang, Y.; Qin, Y.; Weinreb, R.N.; Sun, X. Tissue distribution of trans-resveratrol and its metabolites after oral administration in human eyes. J. Ophthalmol. 2017, 2017, 4052094. [CrossRef] [PubMed]

71. Silva, C.G.; Monteiro, J.; Marques, R.R.; Silva, A.M.; Martínez, C.; Canle, M.; Faria, J.L. Photochemical and photocatalytic degradation of trans-resveratrol. Photochem. Photobiol. Sci. 2013, 12, 638-644. [CrossRef] [PubMed]

72. Alambiaga-Caravaca, A.M.; Calatayud-Pascual, M.A.; Rodilla, V.; Concheiro, A.; López-Castellano, A.; Alvarez-Lorenzo, C. Micelles of progesterone for topical eye administration: Interspecies and intertissues differences in ex vivo ocular permeability. Pharmaceutics 2020, 12, 702. [CrossRef] [PubMed]

73. Luensmann, D.; Jones, L. Protein deposition on contact lenses: The past, the present, and the future. Contact Lens Anterior Eye 2012, 35, 53-64. [CrossRef]

74. Carapeto, A.; Serro, A.; Nunes, B.; Martins, M.; Todorovic, S.; Duarte, M.T.; Andre, V.; Colaco, R.; Saramago, B. Characterization of two DLC coatings for joint prosthesis: The role of albumin on the tribological behavior. Surf. Coat. Technol. 2010, 204, 3451-3458. [CrossRef]

75. Gispert, M.P.; Serro, A.P.; Colaço, R.; Saramago, B. Bovine serum albumin adsorption onto 316L stainless steel and alumina: A comparative study using depletion, protein radiolabeling, quartz crystal microbalance and atomic force microscopy. Surf. Interface Anal. 2008, 40, 1529-1537. [CrossRef]

76. Jin, J.; Han, Y.; Zhang, C.; Liu, J.; Jiang, W.; Yin, J.; Liang, H. Effect of grafted PEG chain conformation on albumin and lysozyme adsorption: A combined study using QCM-D and DPI. Colloid Surf. B 2015, 136, 838-844. [CrossRef] [PubMed]

77. Fulga, F.; Nicolau, D. Biomolecular layers: Quantification of mass and thickness. In Wiley Encyclopedia of Biomedical Engineering; John Wiley \& Sons Inc.: Hoboken, NJ, USA, 2006; Volume 3, pp. 154-196.

78. Al-Sohani, A.; Awwad, S.; Shaw, P.T.; Brocchini, S. The preparation of HEMA-MPC films for ocular drug delivery. Br. J. Pharm. 2017, 2, 31-41. [CrossRef]

79. Yang, J.; Mattison, K. Protein characterization using dynamic and static light scattering. China Particuol. 2003, 1, $219-222$. [CrossRef]

80. Silva, D.; de Sousa, H.C.; Gil, M.H.; Santos, L.F.; Amaral, R.A.; Saraiva, J.A.; Salema-Oom, M.; Alvarez-Lorenzo, C.; Serro, A.P.; Saramago, B. Imprinted hydrogels with LbL coating for dual drug release from soft contact lenses materials. Mater. Sci. Eng. C Mater. Biol. Appl. 2021, 120, 111687. [CrossRef]

81. Garrett, Q.; Garrett, R.W.; Milthorpe, B.K. Lysozyme sorption in hydrogel contact lenses. Investig. Ophthalmol. Vis. Sci. 1999, 40, 897-903.

82. Diaz-Gomez, L.; Concheiro, A.; Alvarez-Lorenzo, C. Functionalization of titanium implants with phase-transited lysozyme for gentle immobilization of antimicrobial lysozyme. Appl. Surf. Sci. 2018, 452, 32-42. [CrossRef]

83. Shimamura, Y.; Hirai, C.; Sugiyama, Y.; Shibata, M.; Ozaki, J.; Murata, M.; Ohashi, N.; Masuda, S. Inhibitory effects of food additives derived from polyphenols on staphylococcal enterotoxin A production and biofilm formation by Staphylococcus aureus Biosci. Biotechnol. Biochem. 2017, 81, 2346-2352. [CrossRef] [PubMed]

84. Mah, T.F.; O’Toole, G.A. Mechanisms of biofilm resistance to antimicrobial agents. Trends Microbiol. 2001, 9, 34-39. [CrossRef]

85. Van Meerloo, J.; Kaspers, G.J.; Cloos, J. Cell sensitivity assays: The MTT assay. Methods Mol. Biol. 2011, 731, $237-245$.

86. Stepanenko, A.A.; Dmitrenko, V.V. Pitfalls of the MTT assay: Direct and off-target effects of inhibitors can result in over/underestimation of cell viability. Gene 2015, 574, 193-203. [CrossRef] [PubMed]

87. Lee, K.; Lee, J.H.; Ryu, S.Y.; Cho, M.H.; Lee, J. Stilbenes reduce Staphylococcus aureus hemolysis, biofilm formation, and virulence. Foodborne Pathog. Dis. 2014, 11, 710-717. [CrossRef] [PubMed]

88. Cho, H.S.; Lee, J.H.; Cho, M.H.; Lee, J. Red wines and flavonoids diminish Staphylococcus aureus virulence with anti-biofilm and anti-hemolytic activities. Biofouling 2015, 31, 1-11. [CrossRef] [PubMed]

89. Fujii, K.; Matsumoto, H.N.; Koyama, Y.; Iwasaki, Y.; Ishihara, K.; Takakuda, K. Prevention of biofilm formation with a coating of 2-methacryloyloxyethyl phosphorylcholine polymer. J. Vet. Med. Sci. 2008, 70, 167-173. [CrossRef] [PubMed]

90. Willcox, M.D.P.; Harmis, N.; Cowell, B.A.; Williams, T.; Holden, B.A. Bacterial interactions with contact lenses; effects of lens material, lens wear and microbial physiology. Biomaterials 2001, 22, 3235-3247. [CrossRef]

91. Bruinsma, G.M.; Van der Mei, H.C.; Busscher, H.J. Bacterial adhesion to surface hydrophilic and hydrophobic contact lenses. Biomaterials 2001, 22, 3217-3224. [CrossRef]

92. Henriques, M.; Sousa, C.; Lira, M.; Elisabete, M.; Oliveira, R.; Oliveira, R.; Azeredo, J. Adhesion of Pseudomonas aeruginosa and Staphylococcus epidermidis to silicone-hydrogel contact lenses. Optom. Vis. Sci. 2005, 82, 446-450. [CrossRef] 